This document is the Accepted Manuscript version of a Published Work that appeared in final form in Journal of Physical Chemistry C, copyright (c) American Chemical society after peer review and technical editing by the publisher. To access the final edited and published work see https://pubs.acs.org/doi/abs/10.1021/acs.jpcc.6b11710

\title{
Adsorption of Chlorinated Methane Derivatives at the Ice Surface. A Grand Canonical Monte Carlo Simulation Study
}

\author{
Ildikó Sumi $^{\mathrm{a}}$, Sylvain Picaud ${ }^{\mathrm{b}}$, Pál Jedlovszky ${ }^{\mathrm{a}, \mathrm{c}, *}$ \\ a Department of Chemistry, Eszterházy Károly University, Leányka u. 6, H-3300 \\ Eger, Hungary \\ ${ }^{\mathrm{b}}$ Institut UTINAM (CNRS UMR 6213), Université Bourgogne Franche-Comté, 16 \\ route de Gray, F-25030 Besançon, France \\ ${ }^{\mathrm{c}}$ MTA-BME Research Group of Technical Analytical Chemistry, Szt. Gellért tér \\ 4, H-1111 Budapest, Hungary
}

Running title: Adsorption of chlorinated methane derivatives at ice

*E-mail: jedlovszky.pal@uni-eszterhazy.hu, phone: +36-20-9881527 


\section{Abstract:}

The adsorption behavior of three chlorinated methane derivative molecules, namely $\mathrm{CH}_{3} \mathrm{Cl}, \mathrm{CHCl}_{3}$, and $\mathrm{CCl}_{4}$ is investigated at the (0001) surface of $\mathrm{I}_{\mathrm{h}}$ ice at the tropospheric temperature of $200 \mathrm{~K}$ by means of grand canonical Monte Carlo simulations. This study completes our earlier investigations concerning the adsorption of $\mathrm{CH}_{4}, \mathrm{CH}_{2} \mathrm{Cl}_{2}$, and fluorinated methane derivatives. Our results show that neither $\mathrm{CHCl}_{3}$ nor $\mathrm{CCl}_{4}$ exhibits any adsorption. This complete lack of adsorption is attributed to the interplay of the very strong cohesion acting between the adsorbate molecules, and their relatively weak interaction with the ice phase. By contrast, $\mathrm{CH}_{3} \mathrm{Cl}$ does exhibit noticeable adsorption on ice, and the adsorbed molecules prefer to turn towards the ice surface by their $\mathrm{H}$ atoms, forming weak, $\mathrm{C}-\mathrm{H}^{\cdots \cdots} \mathrm{O}$ type hydrogen bonds with surface waters. The lateral (i.e., adsorbate-adsorbate) contribution to the total interaction energy of the adsorbed molecules is always considerably larger (in magnitude) than in the case of the corresponding fluorinated analogs, making also the total adsorption energy lower for the chlorinated molecules than for their fluorinated counterpart. As a consequence of this strong attraction between the chlorinated adsorbate molecules, their condensation occurs at lower chemical potential (and, hence, pressure) values than that of the fluorinated analogs, which prevents the formation or completion of the adsorption layer of the chlorinated molecules. 


\section{Introduction}

Characterizing the adsorption processes at the ice surface is of fundamental importance in atmospheric sciences. Indeed, ice particles forming the polar stratospheric clouds (PSCs) have been recognized to participate in the chemistry of halogenated molecules in the troposphere that finally leads to the efficient catalytic destruction of ozone by halogenated free radicals. ${ }^{1,2}$ At lower altitudes, the selective trapping of various atmospheric pollutants at the surface of cirrus ice particles may be responsible for their partitioning from the gas to the ice phase, impacting thus on atmospheric chemistry. ${ }^{3}$ Adsorbed species on ice can also be scavenged from the troposphere by falling snow. ${ }^{4}$ Finally, the snowcap covering up to $50 \%$ of the landmass in the Northern Hemisphere ${ }^{5}$ offers a large internal surface for interactions with atmospheric gases, where the trapped gases may undergo specific oxidative and/or photochemical processes that also have an impact on atmospheric chemistry. ${ }^{6,7}$

The adsorption properties of many atmospheric species on ice have thus been widely characterized (see, e.g., the reviews by Abbatt, ${ }^{8}$ Huthwelker et al., ${ }^{9}$ and Bartels-Rausch et al., ${ }^{10}$ and also the compilation of kinetic and photochemical data by Crowley et al. ${ }^{11}$ ). Among these species, halocarbon molecules have received significant attention, ${ }^{12}$ not only because of their role in ozone destruction cycles, but also because some of these molecules are known to have a strong climate forcing effect. ${ }^{13}$ However, in the series of the experimental studies devoted to the characterization of the halocarbon-ice interactions, halomethane molecules were only considered a few times. In addition, most of these studies were based on the standard techniques of surface science, being thus performed far below the atmospherically relevant temperature range. Thus, Blanchard and Roberts, ${ }^{14}$ and later Sadtchenko et al. ${ }^{15,16}$ characterized the interaction of $\mathrm{CCl}_{4}$ with ice using temperature programmed desorption (TPD) up to $130 \mathrm{~K}$, and concluded that the intermolecular forces between this molecule and ice are quite weak, being typical of a physisorption process. They also showed that the adsorption state of $\mathrm{CCl}_{4}$ on amorphous ice depends on the surface coverage. Holmes and Sodeau used infrared (IR) spectroscopy to study the interaction of a large series of twenty-three halomethane molecules with ice at $12 \mathrm{~K} .{ }^{17}$ They found that all these molecules interact via hydrogen bonding interaction between the surface waters and the halogen atom. As a consequence, the IR shift of the corresponding dangling H-bond was shown to strongly depend 
on the type of the halomethane molecule. ${ }^{17}$ Schaff and Roberts focused on the adsorbed states of chloroform $\left(\mathrm{CHCl}_{3}\right)$ on amorphous and crystalline ice by means of $\mathrm{X}$-ray photoelectron spectroscopy. ${ }^{18}$ They evidenced significant differences between the monolayer and multilayer adsorption states of $\mathrm{CHCl}_{3}$ on crystalline ice, but found a single chloroform state on amorphous ice, irrespective of the surface coverage. The different adsorption behavior on crystalline and amorphous ices was later confirmed by the different desorption temperatures observed in TPD experiments. ${ }^{19}$ In these experiments, it was also shown that the chloroform molecules remain immobile at the ice surface up to the desorption temperature. A similar result was obtained later by Pysanenko et al. considering $\mathrm{CH}_{3} \mathrm{Cl}$ molecules adsorbed on ice, who concluded that the interaction with the polar water molecules inhibits the mobility of the adsorbed molecules. $^{20}$ Moreover, it was also shown by means of metastable impact electron spectroscopy that $\mathrm{CHCl}_{3}$ molecules are adsorbed at the ice surface with their $\mathrm{H}$ atom oriented towards the substrate below $120 \mathrm{~K},{ }^{21}$ and for all chlorinated methane derivatives $\left(\mathrm{CH}_{4-\mathrm{x}} \mathrm{Cl}_{\mathrm{x}}\right)$ that their interaction with water occurs through the oxygen atom. ${ }^{22}$ Finally, Vysokikh et al. focused on the interaction of ozone with $\mathrm{CH}_{4-\mathrm{x}} \mathrm{Cl}_{\mathrm{x}}$ molecules adsorbed on a thin ice film over the temperature range of 77-292 K, and showed that these molecules cannot dissociate at the surface on ice, and therefore do not release chlorine, at least below $210 \mathrm{~K}^{23}$

Despite these series of experimental studies, several questions remained open concerning the atomistic details of the interaction processes between chloromethane molecules and water at the ice surface, especially in the temperature range relevant for the upper troposphere - lower stratosphere (UTLS) region. Indeed, neither the orientation of the adsorbed molecules nor their exact location (i.e., above or within the surface layers of ice) are known in this temperature range. This information would, however, be of crucial importance to characterize the reactivity and photoreactivity of chloromethane molecules trapped by atmospheric ice particles or snow cover, and then better assess their exact role, for instance, in ozone destruction cycles. ${ }^{2}$ In addition, it would also be important to know what kind of behavior (i.e., Langmuir or not) their trapping at the ice surface exhibits, in order to better quantify the possible amount of chloromethanes that could be scavenged from the atmosphere, and thus improve our knowledge on the possible sinks for these molecules. These questions can conveniently be studied by computer simulation methods, as they can provide an insight at the atomistic level into a suitably chosen model of the system to be studied. Among the various 
computer simulation methods, grand canonical Monte Carlo (GCMC) ${ }^{24,25}$ is particularly suitable for such studies, as in GCMC simulations the chemical potential rather than the number of the molecules is fixed. Thus, performing a set of GCMC simulations, in which the chemical potential of the adsorbate is systematically varied, the adsorption isotherm, i.e., the number of the adsorbed molecules as a function of their chemical potential can be conveniently calculated, and this function can then be converted to a more conventional (e.g., pressure dependent) form. Indeed, the GCMC method has been applied for studying the adsorption of several small molecules at various solid surfaces, including silicate minerals, such as kaolinite $^{26,27}$ or zeolites, ${ }^{28-34}$ metal oxides, ${ }^{35-38}$ carbonaceous materials, ${ }^{39-45}$ covalent organic frameworks, ${ }^{46-48}$ self-assembled monolayers, ${ }^{49,50}$ and protein crystals. ${ }^{51}$ This method has also been widely applied for studying the adsorption of a number of adsorbates at the surface of ice ${ }^{52-60}$ because the determination of the full adsorption isotherm is of central importance in addressing both the degree to which an atmospheric species partitions between the surface of ice and the gas phase, and also the corresponding mechanism. In this way, the extent of gas-toice scavenging can be estimated, and this information can be incorporated into the various atmospheric models. ${ }^{8}$

The adsorption of halogenated methane derivatives at the surface of water or ice has, however, only been studied by computer simulation methods a handful of times. In an early study, we calculated the solvation free energy profile of $\mathrm{CH}_{2} \mathrm{~F}_{2}, \mathrm{CH}_{2} \mathrm{Cl}_{2}$, and $\mathrm{CHCl}_{3}$ across the ice-vapor and water-vapor interfaces. ${ }^{61}$ Later, Habartová et al. calculated this profile across the water-vapor interface for all the partially chlorinated and brominated methane derivatives. ${ }^{62}$ They also performed molecular dynamics simulations studying the properties of these molecules at the ice surface at infinite dilution, i.e., having one single adsorbate molecule at the ice surface. ${ }^{63}$ Harper et al. studied the adsorption of $\mathrm{CH}_{3} \mathrm{Cl}$ and $\mathrm{CH}_{3} \mathrm{Br}$ at the air/water interface at room temperature by vibrational sum frequency spectroscopy measurements as well as molecular dynamics simulations. ${ }^{64}$ Recently, using GCMC simulations, we compared the adsorption behavior of $\mathrm{CH}_{2} \mathrm{~F}_{2}$ and $\mathrm{CH}_{2} \mathrm{Cl}_{2}$ at the surface of ice, and found that, due to its large cohesion, $\mathrm{CH}_{2} \mathrm{Cl}_{2}$ condenses even before the first adsorption monolayer could be built up. ${ }^{58} \mathrm{We}$ also compared the adsorption behavior of methane and all the four different fluorinated methane derivatives (i.e., molecules described by the general formula $\mathrm{CH}_{n} \mathrm{~F}_{4-n}$ ), and found that the molecules having a net dipole moment exhibit at least traces of multilayer adsorption. ${ }^{59}$ 
In the present study, we complete our earlier set of investigations by calculating the adsorption isotherm of the full set of differently chlorinated methane derivatives, i.e., molecules corresponding to the general formula $\mathrm{CH}_{n} \mathrm{Cl}_{4-n}$, at the surface of $\mathrm{I}_{\mathrm{h}}$ ice at the tropospheric temperature of $200 \mathrm{~K}$. Since the isotherm of $\mathrm{CH}_{2} \mathrm{Cl}_{2}$ has already been calculated previously, ${ }^{58}$ we present new calculations concerning the adsorption of $\mathrm{CH}_{3} \mathrm{Cl}, \mathrm{CHCl}_{3}$, and $\mathrm{CCl}_{4}$. The set of these compounds is completed by $\mathrm{CH}_{4}$, regarded here as a reference adsorbate, the adsorption isotherm of which has also been calculated previously. ${ }^{59}$

\section{Computer Simulations}

The adsorption of $\mathrm{CH}_{3} \mathrm{Cl}, \mathrm{CHCl}_{3}$ and $\mathrm{CCl}_{4}$ at the (0001) surface of $\mathrm{I}_{\mathrm{h}}$ ice has been studied at the tropospheric temperature of $200 \mathrm{~K}$ by performing a set of Monte Carlo simulations on the grand canonical $(\mu, V, T)$ ensemble for each adsorbate, in which the chemical potential of the adsorbate, $\mu$, has been systematically varied from values corresponding to practically no molecules being in the simulation box to values corresponding to the condensed phase of the adsorbate. The set of the adsorbate chemical potential values corresponding to the simulations are collected in Tables 1-3. The simulations have been performed in the same way as done previously when studying the adsorption of $\mathrm{CH}_{2} \mathrm{Cl}_{2}{ }^{58}$ and $\mathrm{CH}_{4}{ }^{59}$ Thus, the $X, Y$ and $\mathrm{Z}$ edge lengths of the rectangular basic simulation box have been $100 \AA, 35.926 \AA$, and $38.891 \AA$, respectively, $X$ being the interface normal axis. The $Y$ and $Z$ edge lengths have been chosen in accordance with the periodicity of the $I_{h}$ ice crystal. The basic box has consisted of 2880 water molecules, arranged in 18 molecular layers along the $X$ axis. This way, the two ice surfaces have been separated from each other by a roughly $35 \AA$ wide vapor layer. At the beginning of the simulations the arrangement of the water molecules corresponded to the structure of the perfect (proton-disordered) $\mathrm{I}_{\mathrm{h}}$ ice crystal, and two adsorbate molecules were randomly placed in the vapor phase of the system. Standard periodic boundary conditions have been applied in all directions.

The $\mathrm{CH}_{3} \mathrm{Cl}$ molecules have been modeled by the general AMBER force field (GAFF), ${ }^{65}$ using the charge distribution proposed by Habartová et al. ${ }^{62}$ The $\mathrm{CHCl}_{3}$ and $\mathrm{CCl}_{4}$ molecules have been described by the potential model proposed by Dietz and Heinzinger, ${ }^{66}$ and by the 
OPLS force field ${ }^{67}$ respectively, while the five site TIP5P potential model ${ }^{68}$ has been used for water, since it describes accurately the melting point of $\mathrm{I}_{\mathrm{h}}$ ice ${ }^{69,70}$ All these potential models are rigid and pairwise additive, thus, the total energy of the system can simply be calculated as the sum of the pair interaction energies of the molecules. The interaction energy of a molecule pair is the sum of the Lennard-Jones and Coulomb contributions of all pairs of their respective interaction sites. Interaction sites of these models are located at the atomic positions, with the exception of the TIP5P water model, which contains also two non-atomic interaction sites in the direction of the lone pairs of the $\mathrm{O}$ atom. ${ }^{68}$ The interaction and geometry parameters of the potential models used are summarized in Tables 4 and 5, respectively. In accordance with the original parametrization of the TIP5P water model, ${ }^{68}$ all interactions have been truncated to zero beyond the center-center cut-off distance of $12.5 \AA$, the $\mathrm{O}$ and $\mathrm{C}$ atoms being regarded as centers of the water and adsorbate molecules, respectively.

To check the sensitivity of the results on the adsorbate potential model used, we have calculated the entire adsorption isotherm of $\mathrm{CH}_{3} \mathrm{Cl}$ also with the OPLS potential model. ${ }^{71} \mathrm{~A}$ few points along the isotherm of $\mathrm{CHCl}_{3}$ have also been recalculated using the OPLS model. ${ }^{72}$ In the case of $\mathrm{CH}_{3} \mathrm{Cl}$, we found a continuous increase of the number of adsorbed molecules as a function of the chemical potential, without observing any sudden jump of these data (see the inset of Figure 1). This observed lack of the point of condensation indicates that there is no vapor-liquid transition in this case, hence, the OPLS model of $\mathrm{CH}_{3} \mathrm{Cl}^{71}$ is already above its critical point at the simulation temperature of $200 \mathrm{~K}$. Considering the fact that the experimental critical point of $\mathrm{CH}_{3} \mathrm{Cl}$ is at $417 \mathrm{~K}^{73}$ it is clear that the OPLS model of $\mathrm{CH}_{3} \mathrm{Cl}$ fails in reproducing the attraction between the molecules, and hence leads to unreliable results, at least from the thermodynamic point of view. In fact, this potential model was originally developed to describe the molecular details of an $\mathrm{S}_{\mathrm{N}} 2$ type reaction, involving a single $\mathrm{CH}_{3} \mathrm{Cl}$ molecule in aqueous environment, without fitting the interaction parameters to the properties of bulk liquid $\mathrm{CH}_{3} \mathrm{Cl}^{71}$ Nevertheless, apart from the results directly related to the strength of the interaction between the adsorbed $\mathrm{CH}_{3} \mathrm{Cl}$ molecules (such as the aforementioned lack of the point of condensation, position of the adsorption isotherm at too high chemical potential values, too small lateral interaction), even this model provided compatible results with the GAFF force field of $\mathrm{CH}_{3} \mathrm{Cl},{ }^{65}$ used in the present analysis. Further, apart from a small shift of the point of 
condensation, the simulations performed with the OPLS model of $\mathrm{CHCl}_{3}{ }^{72}$ have also led to qualitatively the same conclusions as those with the potential model of Dietz and Heinzinger. ${ }^{66}$

The simulations have been performed using the code MMC. ${ }^{74}$ In a Monte Carlo step either a randomly chosen molecule has been attempted to be displaced by a random translation of no more than $0.25 \AA$ and a random rotation around a randomly chosen space-fixes axis by no more than $15^{\circ}$, or the number of the adsorbate molecules has been attempted to be changed by one by either inserting or deleting a molecule. Particle displacement and insertion/deletion attempts have been performed in alternating order; insertion and deletion attempts have been done with equal probabilities, using the cavity biased scheme of Mezei. ${ }^{75,76}$ Thus, particle insertions have only been attempted in cavities of the radius of at least $2.5 \AA$, searched for along a $100 \times 100 \times 100$ grid in the basic simulation box. This grid has been regenerated after every $10^{6}$ Monte Carlo attempts. The probability of finding a suitable cavity, $P_{\text {cav }}$, a quantity needed in performing the acceptance test of the cavity biased insertion/deletion attempts ${ }^{75,76}$ has simply been calculated as the ratio of the number of cavities found and grid points tested. Particle displacement attempts have been accepted or rejected according to the standard Metropolis criterion. ${ }^{25,77}$ This way, at least $10 \%$ of the particle displacement attempts and $0.1 \%$ of the insertion/deletion attempts have turned out to be successful in every case.

The systems have been equilibrated by performing $3 \times 10^{8}$ Monte Carlo steps. The average number of adsorbate molecules present in the basic simulation box, $\langle N\rangle$, has then been calculated in a subsequent $10^{8}$ Monte Carlo steps long equilibrium trajectory. Further, at selected chemical potential values of $\mathrm{CH}_{3} \mathrm{Cl}$ and $\mathrm{CHCl}_{3}$, a sample of 2500 equilibrium configurations, separated from each other by $2 \times 10^{5}$ Monte Carlo steps each, have been dumped for detailed analyses, including the calculation of the adsorbate orientational and binding energy distributions. All properties calculated have not only been averaged over the 2500 sample configurations, but also over the two ice surfaces present in the basic simulation box. Equilibrium snapshot of the ice surface is shown in Figure 2 as obtained at four different chemical potential values of $\mathrm{CH}_{3} \mathrm{Cl}$ as well as at two chemical potential values of both $\mathrm{CHCl}_{3}$ and $\mathrm{CCl}_{4}$. 


\section{Results and Discussion}

3.1. Adsorption Isotherms. The average number of adsorbate molecules in the basic simulation box, $\langle N\rangle$, is shown in Figure 1 as the function of the chemical potential of the adsorbate molecules, $\mu$, as obtained here for $\mathrm{CH}_{3} \mathrm{Cl}, \mathrm{CHCl}_{3}$, and $\mathrm{CCl}_{4}$. The corresponding data are also included in Tables 1, 2 and 3, respectively. For completeness, earlier results concerning $\mathrm{CH}_{4}{ }^{59}$ and $\mathrm{CH}_{2} \mathrm{Cl}_{2}{ }^{58}$ are also shown. As is seen in Fig. 1, neither $\mathrm{CHCl}_{3}$ nor $\mathrm{CCl}_{4}$ show noticeable adsorption, as their mean number in the basic box is very close to zero up to a certain, well defined value of $\mu$, corresponding to the point of condensation, whereas they fill the available space in the basic box above this chemical potential. In this respect, their behavior is rather similar to that of $\mathrm{CH}_{2} \mathrm{Cl}_{2},{ }^{58}$ but clearly differs both from that of $\mathrm{CH}_{3} \mathrm{Cl}$, and from that of their fluorinated analogs (i.e., $\mathrm{CHF}_{3}$ and $\mathrm{CF}_{4}$, respectively), ${ }^{59}$ as these last species all show noticeable adsorption below the point of condensation. The $\langle N\rangle$ vs. $\mu$ data corresponding to $\mathrm{CH}_{3} \mathrm{Cl}$, on the other hand, exhibits a continuous, nearly exponential increase below the point of condensation, similarly to that of its fluorinated analog, $\mathrm{CH}_{3} \mathrm{~F},{ }^{59}$ although to a considerably smaller extent.

In every simulation, practically all the adsorbate molecules present in the basic box have been found to be attached to the ice surface in the entire chemical potential range considered up to the point of condensation. Therefore, the $\langle N\rangle$ vs. $\mu$ data corresponds directly to the adsorption isotherm itself, and can be converted to the conventional $\Gamma$ vs. $p_{\text {rel }}$ form ( $\Gamma$ and $p_{\text {rel }}$ being the surface density and relative pressure, i.e., pressure normalized by that of the point of condensation, $p_{0}$, respectively), using the equations

$$
\Gamma=\frac{<N>}{2 Y Z}
$$

and $^{37}$

$$
p_{\text {rel }}=\frac{p}{p_{0}}=\frac{\exp (\beta \mu)}{\exp \left(\beta \mu_{0}\right)}
$$

respectively. In eq. 1, the factor 2 in the denominator accounts for the two ice surfaces present in the basic box, whereas in eq. $2 \beta=1 / k_{\mathrm{B}} T, k_{\mathrm{B}}$ being the Boltzmann constant, and $\mu_{0}$ is the chemical potential value corresponding to the point of condensation. Based on the obtained 
$<N>$ vs. $\mu$ data, we estimated the value of $\mu_{0}$ to be $-36.29 \mathrm{~kJ} / \mathrm{mol}$ for $\mathrm{CH}_{3} \mathrm{Cl},-37.85 \mathrm{~kJ} / \mathrm{mol}$ for $\mathrm{CHCl}_{3}$, and $-36.41 \mathrm{~kJ} / \mathrm{mol}$ for $\mathrm{CCl}_{4}$.

The obtained $\Gamma$ vs. $p_{\text {rel }}$ isotherms are shown in Figure 3. Again, for completeness, data obtained earlier for $\mathrm{CH}_{4}{ }^{59}$ and $\mathrm{CH}_{2} \mathrm{Cl}_{2}{ }^{58}$ are also included in the figure. As is expected, the $\Gamma$ vs. $p_{\text {rel }}$ data of $\mathrm{CHCl}_{3}$ and $\mathrm{CCl}_{4}$, similarly to those of $\mathrm{CH}_{2} \mathrm{Cl}_{2},{ }^{58}$ are both practically zero below the point of condensation. Showing these data on a magnified scale it is seen that, apart from the highest pressure part of the $\mathrm{CHCl}_{3}$ data, $\Gamma$ increases linearly with $p_{\text {rel, }}$ indicating that the adsorption of a new molecule is independent from the presence or absence of other molecules in the adsorption layer. The positive deviation of the $\mathrm{CHCl}_{3}$ data from this linearity at high pressures can be regarded as a precursor of the condensation, as it indicates that the presence of admolecules at the surface facilitates the adsorption of other molecules at their vicinity. The $\Gamma\left(p_{\text {rel }}\right)$ data of $\mathrm{CH}_{3} \mathrm{Cl}$ exhibits a continuously decreasing slope, without reaching a value of saturation, in the entire $p_{\text {rel }}$ range between 0 and 1 . We tried to fit the Langmuir isotherm ${ }^{78,79}$ to the rising part of the $\Gamma\left(p_{\text {rel }}\right)$ data, using the data points up to $0.46,0.76,0.93$ and 0.975 , but this fitting turned out to be unsuccessful in every case. The non-Langmuir character of the isotherm indicates that the adsorption of the $\mathrm{CH}_{3} \mathrm{Cl}$ molecules is not independent from each other. In other words, there is a non-negligible lateral interaction between them. Unfortunately, we are not aware of any experimental measurements of such isotherms for chloromethane derivatives interacting with crystalline ice at or around $200 \mathrm{~K}$, to which the results of our simulations could be directly compared, as it was done in some of our previous studies devoted to the adsorption of small volatile organic compounds. ${ }^{52,53}$ Nevertheless, future measurements of these isotherms can provide an additional test of the reliability of the present results.

For the purpose of a detailed orientational and energetic analysis of the adsorbed molecules, we have collected 2500 sample configurations at four different chemical potential values of $\mathrm{CH}_{3} \mathrm{Cl}$, and at two chemical potential values of $\mathrm{CHCl}_{3}$. In the case of $\mathrm{CH}_{3} \mathrm{Cl}$, the first $(\mu=-45.89 \mathrm{~kJ} / \mathrm{mol})$ and second $(\mu=-39.24 \mathrm{~kJ} / \mathrm{mol})$ of these chemical potential values correspond to the presence of only a few isolated molecules at the ice surface, and to an unsaturated first molecular layer, respectively, while the third $(\mu=-36.41 \mathrm{~kJ} / \mathrm{mol})$ and fourth $(\mu=-36.08 \mathrm{~kJ} / \mathrm{mol})$ ones are located right below and above the point of condensation, respectively. In the case of $\mathrm{CHCl}_{3}$, the two chemical potential values considered, i.e., $-37.90 \mathrm{~kJ} / \mathrm{mol}$ and $-37.73 \mathrm{~kJ} / \mathrm{mol}$, are located right below and above the point of condensation, 
respectively. The chemical potential values at which these detailed analyses have been performed are indicated in Tables 1 and 2 as well as in Figs. 1 and 3.

3.2. Density Profiles. The density profile of the adsorbed $\mathrm{CH}_{3} \mathrm{Cl}$ and $\mathrm{CHCl}_{3}$ molecules along the interface normal axis, $X$, is shown in Figure 4.a and b, respectively, as obtained at the selected chemical potential values. For comparison, the density profile corresponding to the outmost molecular layer of the ice phase is also shown (as obtained in the system with $\mathrm{CH}_{3} \mathrm{Cl}$ at the $\mu$ value of $-45.89 \mathrm{~kJ} / \mathrm{mol}$ ). The water number density profile across the entire ice phase is shown in the inset of the figure.

At $\mu=-45.89 \mathrm{~kJ} / \mathrm{mol}$ the $\mathrm{CH}_{3} \mathrm{Cl}$ molecules form a highly unsaturated monolayer at the ice surface. Upon approaching the point of condensation, this monolayer becomes progressively more saturated, as evidenced by the gradual increase of the density peak located always at the same position of about $|X|=34 \AA$, i.e., at a contact distance from the ice surface. At $\mu=-36.41 \mathrm{~kJ} / \mathrm{mol}$, i.e., right below the point of condensation, this monolayer is nearly saturated (as the amplitude of this density peak almost reaches that in the bulk liquid phase of $\mathrm{CH}_{3} \mathrm{Cl}$ ), and a small trace of a second molecular layer also occurs around the $|X|$ value of $37.4 \AA$. However, the building up of this second molecular layer is prevented by the condensation of $\mathrm{CH}_{3} \mathrm{Cl}$, occurring at an about $0.1 \mathrm{~kJ} / \mathrm{mol}$ higher chemical potential value. Above the point of condensation, the density profile shows the typical damped oscillation characteristic of the liquid phase. It is also clear from the figure that up to the point of condensation, $\mathrm{CHCl}_{3}$ forms a highly unsaturated monolayer, while above that it forms a bulk liquid phase.

In the following analyses only the molecules that are forming the first adsorption layer (i.e., that are directly attached to the ice surface) have been taken into account. The outer boundary of the first molecular layer is defined as the position of the first minimum of the adsorbate density profile in the liquid phase (see Fig. 4). This way, the molecules the $\mathrm{C}$ atom of which is located below the $|X|$ value of $36.2 \AA$, in the case of $\mathrm{CH}_{3} \mathrm{Cl}$, and $36.5 \AA$, in the case of $\mathrm{CHCl}_{3}$, are considered to be in the first molecular layer.

3.3. Orientation of the Adsorbed Molecules. Describing the orientation of a rigid molecule relative to an external plane requires the use of two independent orientational 
variables. Therefore, describing the orientational statistics can only be done unambiguously by using the bivariate joint distribution of these variables. ${ }^{80,81}$ We showed that the angular polar coordinates, $\vartheta$ and $\phi$, of the vector perpendicular to the external plane (in the present case, the surface normal vector) in a local Cartesian frame fixed to the individual molecules represent a sufficient choice of such a variable pair. However, uncorrelated orientation of the molecules with the surface results in a uniform distribution only if $\cos \vartheta$ and $\phi$ are used as orientational variables. ${ }^{80,81}$

Here we define this local Cartesian frame in the following way. The main symmetry axis of the molecule, described by the general formula of $\mathrm{CXY}_{3}$ (where $\mathrm{X}$ stands for $\mathrm{Cl}$ and $\mathrm{Y}$ for $\mathrm{H}$ in $\mathrm{CH}_{3} \mathrm{Cl}$, while $\mathrm{X}$ and $\mathrm{Y}$ stand for $\mathrm{H}$ and $\mathrm{Cl}$, respectively, in $\mathrm{CHCl}_{3}$ ) corresponds to the $z$ axis of this frame, oriented in such a way that it points from atom $\mathrm{X}$ to the central $\mathrm{C}$ atom. Axis $x$ is defined by the condition that one of the three $\mathrm{Y}$ atoms lies within the $y z$ plane of the frame, while axis $y$ is perpendicular to $x$ and $z . \vartheta$ and $\phi$ are then the angular polar coordinates of the surface normal vector, $\underline{X}$, pointing, by our convention, away from the ice phase, in this frame. Thus, $\vartheta$ is the angle between $\underline{X}$ and axis $z$, while $\phi$ is the angle between the projection of $\underline{X}$ onto the $x y$ plane and axis $x$. Due to the $\mathrm{C}_{3 \mathrm{v}}$ symmetry of the molecules considered, this frame can always be chosen to satisfy the inequality of $0^{\circ} \leq \phi<60^{\circ}$. The definition of this local Cartesian frame as well as that of the polar angles $\vartheta$ and $\phi$ are illustrated in Figure 5.

The $P(\cos \vartheta, \phi)$ orientational maps of the $\mathrm{CH}_{3} \mathrm{Cl}$ and $\mathrm{CHCl}_{3}$ molecules belonging to the first molecular layer at the ice surface are shown in Figure 6 as obtained at the adsorbate chemical potential values considered. In the case of $\mathrm{CH}_{3} \mathrm{Cl}$, the preferential orientation of the molecules corresponds to $\cos \vartheta=-1$ at every chemical potential value considered, and this orientational preference becomes somewhat weaker with increasing surface coverage. It should be noted that in the case of $\cos \vartheta=-1$, the projection of the vector $\underline{X}$ to onto the $x y$ plane of the local frame becomes a single point, and thus angle $\phi$ loses its meaning. As a consequence, all points of the $P(\cos \vartheta, \phi)$ map laying along the $\cos \vartheta=-1$ line correspond to the same orientation. In this orientation, denoted here as $\mathrm{I}_{\mathrm{CH} 3 \mathrm{Cl}}$, the $\mathrm{C}-\mathrm{Cl}$ bond stays perpendicular to the ice surface, pointing the $\mathrm{Cl}$ atom away from the ice phase, while the three $\mathrm{H}$ atoms point flatly towards the ice surface. This orientation, illustrated also in Fig. 6, agrees perfectly with what was previously found to be preferred by $\mathrm{CH}_{3} \mathrm{~F},{ }^{59}$ and agrees also well with the earlier finding of 
Harper et al. concerning the preferred orientation of $\mathrm{CH}_{3} \mathrm{Cl}$ at the free water surface. ${ }^{64}$ It should also be noted that this orientational preference is somewhat different from what was claimed to be the preferred orientation of $\mathrm{CH}_{3} \mathrm{Cl}$ and $\mathrm{CH}_{3} \mathrm{Br}$ by Habartová et al. ${ }^{63}$

In the case of $\mathrm{CHCl}_{3}$, we have found two preferred orientations, both corresponding to slightly negative $\cos \vartheta$ values. The first of these orientations, denoted here as $\mathrm{I}_{\mathrm{CHCl} 3}$, corresponds to $\phi=0^{\circ}$, while in the case of the second one, marked here as $\mathrm{II}_{\mathrm{CHCl} 13}$, the value of $\phi$ is close to $60^{\circ}$. In both of these orientations, the $\mathrm{C}-\mathrm{H}$ bond is nearly parallel with the ice surface, tilting slightly away from the ice phase, and this tilt is somewhat stronger in the presence of the bulk liquid phase. In orientation $\mathrm{I}_{\mathrm{CHCl} 3}$, one $\mathrm{C}-\mathrm{Cl}$ bond points as straight away from the ice phase as possible (within the constraint set by the alignment of the $\mathrm{C}-\mathrm{H}$ bond), while the other two such bonds point equally towards the surface. Conversely, in orientation $\mathrm{II}_{\mathrm{CHCl3}}$ two $\mathrm{C}-\mathrm{Cl}$ bonds point away from, and the third one as straight as possible towards the ice surface. It should be noted that the $\mathrm{CHCl}_{3}$ molecule can form at least one hydrogen bond with a surface water, oriented in one of its preferred alignments, ${ }^{52}$ in both of these orientations The observed orientational preferences are again in a clear agreement with our previous findings for $\mathrm{CHF}_{3},{ }^{59}$ and are also compatible with our earlier results obtained for $\mathrm{CHCl}_{3}$, using different potential models and also considerably higher surface densities than what has been found here to precede condensation. ${ }^{82}$ Besides the orientation corresponding to the $\mathrm{C}-\mathrm{H}$ bond laying (nearly) parallel with the ice surface, we also found in this study preference for the orientation in which the $\mathrm{H}$ atom points straight to the ice surface. ${ }^{82}$ The present results suggest that this latter orientation becomes preferred only at unrealistically high surface densities.

3.4. Energetic Background of the Adsorption. To analyze also the energetic background of the adsorption, we have calculated the distribution of the binding energy, $U_{\mathrm{b}}$, (i.e., total interaction energy with the rest of the system) of the $\mathrm{CH}_{3} \mathrm{Cl}$ and $\mathrm{CHCl}_{3}$ molecules belonging to the first molecular layer at the ice surface at the selected chemical potential values. In addition, the distribution of the interaction energy with the ice phase $\left(U_{\mathrm{b}}^{\text {ice }}\right)$ and with the other adsorbate molecules $\left(U_{\mathrm{b}}^{\text {lat }}\right)$ have also been calculated. The binding energy distributions obtained for $\mathrm{CH}_{3} \mathrm{Cl}$ and $\mathrm{CHCl}_{3}$ are shown in Figures 7.a and b, respectively. 
In the case of $\mathrm{CH}_{3} \mathrm{Cl}$, the $P\left(U_{\mathrm{b}}^{\text {ice }}\right)$ distribution exhibits a single peak in every case. At very low surface coverage, this peak is located at $-42 \mathrm{~kJ} / \mathrm{mol}$, and shifts to higher energies with increasing surface coverage. In the case when the first molecular layer of $\mathrm{CH}_{3} \mathrm{Cl}$ is saturated, the position of this peak is located around $-20--25 \mathrm{~kJ} / \mathrm{mol}$. This finding indicates that the interaction of $\mathrm{CH}_{3} \mathrm{Cl}$ with the ice phase is somewhat stronger than that of $\mathrm{CH}_{3} \mathrm{~F}$, as in this case the positions of the corresponding peaks were found to be around $-30 \mathrm{~kJ} / \mathrm{mol}$ and $-20 \mathrm{~kJ} / \mathrm{mol}$, respectively. ${ }^{59}$ Considering that the energy of a weak, $\mathrm{C}-\mathrm{H}^{\cdots \cdots} \mathrm{O}$ type hydrogen bond is supposed to be around $-10--12 \mathrm{~kJ} / \mathrm{mol}$, and that the adsorbed $\mathrm{CH}_{3} \mathrm{Cl}$ molecules prefer such an orientation at the ice surface in which all the three $\mathrm{H}$ atoms turn towards the ice phase, we can conclude that at low surface coverages these molecules form three such weak H-bonds with the surface water molecules, and maintain two of these H-bonds even when the first layer is saturated. The mean value of the $P\left(U_{\mathrm{b}}^{\text {ice }}\right)$ distribution at the $\mu$ value corresponding to very low surface coverage is $-40.3 \mathrm{~kJ} / \mathrm{mol}$. This value can serve as an estimate of the heat of adsorption at infinitely low surface coverage. Since this is an experimentally accessible quantity, its measurement in the future can provide an important test of the validity of the model used here, and thus also that of this study.

The $P\left(U_{\mathrm{b}}^{\text {lat }}\right)$ distribution of $\mathrm{CH}_{3} \mathrm{Cl}$ is bimodal at low surface coverage. The main peak at zero energy reflects the molecules that are isolated from the other adsorbed molecules, while the second peak around $-6 \mathrm{~kJ} / \mathrm{mol}$ is given by the adsorbed $\mathrm{CH}_{3} \mathrm{Cl}$ dimers, i.e., molecule pairs that are located at the vicinity of each other. At intermediate surface coverage (i.e., at $\mu=-39.24 \mathrm{~kJ} / \mathrm{mol}$ ), the zero energy peak turns to a shoulder, and it disappears upon further increasing the surface coverage (evidencing the disappearance of the isolated adsorbed molecules), while the other peak, which remains the only peak of the distribution, shifts to lower energy values due to the increasing lateral interaction. In the presence of liquid $\mathrm{CH}_{3} \mathrm{Cl}$, the position of the $P\left(U_{\mathrm{b}}^{\text {lat }}\right)$ peak is around $-42 \mathrm{~kJ} / \mathrm{mol}$. This value is rather close to what was previously found for $\mathrm{CH}_{2} \mathrm{Cl}_{2}$, i.e., $-40 \mathrm{~kJ} / \mathrm{mol},{ }^{58}$ and it is considerably lower than that for $\mathrm{CH}_{3} \mathrm{~F}$, i.e., $-22 \mathrm{~kJ} / \mathrm{mol}^{59}$

In the case of $\mathrm{CHCl}_{3}$, the $P\left(U_{\mathrm{b}}^{\text {ice }}\right)$ distribution is peaked around $-20 \mathrm{~kJ} / \mathrm{mol}$. This value is similar to what was found earlier for $\mathrm{CH}_{2} \mathrm{Cl}_{2},{ }^{58}$ but it is considerably smaller (in magnitude) 
than the value of $-30 \mathrm{~kJ} / \mathrm{mol}$ obtained earlier for $\mathrm{CHF}_{3} .{ }^{59}$ Considering the fact that the energy of a H-bonded molecule pair is also around -20 - -25 kJ/mol (considering $\mathrm{OH}$-donated hydrogen bonds), and also that the preferred orientation of the $\mathrm{CHCl}_{3}$ molecules allows their $\mathrm{H}$-bonding with the surface water molecules, it is sensible to assume that the $\mathrm{CHCl}_{3}$ molecules at the ice surface are stabilized by a relatively weak such hydrogen bond, formed with a surface water molecule. This conclusion is also compatible with the results of several earlier experiments, showing that $\mathrm{CHCl}_{3}$ is immobilized at the ice surface ${ }^{19}$, or directly evidencing it being $\mathrm{H}$ bonded to the surface water molecules. ${ }^{17,22}$ The heat of adsorption at infinitely low surface coverage, i.e., an experimentally accessible quantity, is estimated from the mean value of the $P\left(U_{\mathrm{b}}^{\text {ice }}\right)$ distribution below the point of condensation as $-20.5 \mathrm{~kJ} / \mathrm{mol}$. This value is also in a reasonable agreement with our earlier finding, obtained at substantially higher surface coverages employing a different potential model both for water and for $\mathrm{CHCl}_{3}{ }^{82}$ Besides the main peak around $-20 \mathrm{~kJ} / \mathrm{mol}$, the $P\left(U_{\mathrm{b}}^{\text {ice }}\right)$ distribution exhibits also a shoulder around $-10 \mathrm{~kJ} / \mathrm{mol}$ in the presence of the condensed phase of $\mathrm{CHCl}_{3}$, which corresponds to $\mathrm{CHCl}_{3}$ molecules having less favorable interaction with the surface waters due to the increased competition within the surface layer.

The $P\left(U_{\mathrm{b}}^{\text {lat }}\right)$ distribution of $\mathrm{CHCl}_{3}$ is bimodal below the point of condensation. The zero energy peak is given by the isolated molecules, while that around $-5 \mathrm{~kJ} / \mathrm{mol}$ can be attributed to the adsorbed $\mathrm{CHCl}_{3}$ dimers. The energy value at which this latter peak is located is again compatible with our earlier findings, obtained at higher surface coverages using different potential models. ${ }^{82}$ In the case of liquid $\mathrm{CHCl}_{3}$, the $P\left(U_{\mathrm{b}}^{\text {lat }}\right)$ distribution is of Gaussian shape, located around the $U_{\mathrm{b}}^{\text {lat }}$ value of $-45 \mathrm{~kJ} / \mathrm{mol}$, and reflects the interaction not only with the other first layer $\mathrm{CHCl}_{3}$ molecules, but also with those inside the bulk liquid phase. This peak again occurs at considerably lower energies than in the case of the fluorinated analog, i.e., $\mathrm{CHF}_{3}$, for which the position of the corresponding peak is at $-28 \mathrm{~kJ} / \mathrm{mol}{ }^{59}$ This difference reflects the considerably stronger intermolecular attraction acting between the $\mathrm{CHCl}_{3}$ than between the $\mathrm{CHF}_{3}$ molecules, and can explain the different adsorption behavior of these molecules. Thus, $\mathrm{CHF}_{3}$ molecules are bound considerably stronger to the ice phase than $\mathrm{CHCl}_{3}$, which leads to the formation of not only a saturated adsorption monolayer, but also to 
the appearance of traces of outer molecular layers. On the other hand, the weaker ice-adsorbate interaction in the case of $\mathrm{CHCl}_{3}$ is coupled to a markedly stronger cohesion, which together leads to the condensation of $\mathrm{CHCl}_{3}$ before even traces of an adsorption monolayer could have been formed. Similar difference was found earlier in the adsorption behavior of $\mathrm{CH}_{2} \mathrm{~F}_{2}$ and $\mathrm{CH}_{2} \mathrm{Cl}_{2},{ }^{58}$ and, although to a smaller extent, also in that of $\mathrm{CH}_{3} \mathrm{~F}$ and $\mathrm{CH}_{3} \mathrm{Cl}$.

The distribution of the total binding energy, $P\left(U_{\mathrm{b}}\right)$, reflects the same features as what were already seen from the distributions of the ice and lateral contributions. At low surface coverages, when the lateral contribution to the total binding energy is small, the $P\left(U_{\mathrm{b}}\right)$ distribution is rather similar to $P\left(U_{\mathrm{b}}^{\text {ice }}\right)$, its peak being located at almost the same position as that of the ice contribution for both adsorbates. Below the point of condensation, the position of this peak is rather insensitive to the surface coverage, as the increasing lateral contribution to the binding energy is largely compensated by the decrease of the ice contribution due to the increasing competition of the molecules for the adsorption sites. However, above the point of condensation the $P\left(U_{\mathrm{b}}\right)$ distribution is shifted to considerably lower energies, as in this case $U_{\mathrm{b}}$ not only contains the interaction energy of the adsorbed molecules with the ice phase and the first adsorption layer, but also that with their own bulk liquid phase. Thus, above the point of condensation the $P\left(U_{\mathrm{b}}\right)$ distribution peak is located at about $-64 \mathrm{~kJ} / \mathrm{mol}$ in both cases, i.e., close to the position of the similar peak of $\mathrm{CH}_{2} \mathrm{Cl}_{2}$ of $-57 \mathrm{~kJ} / \mathrm{mol},{ }^{58}$ and substantially below the position of the same peak obtained both for their fluorinated analogs (i.e., $-39 \mathrm{~kJ} / \mathrm{mol}$ for $\mathrm{CH}_{3} \mathrm{~F}$ and $-48 \mathrm{~kJ} / \mathrm{mol}$ for $\left.\mathrm{CHF}_{3}\right){ }^{59}$

\section{Summary and Conclusions}

In this paper, we have investigated the adsorption behavior of chlorinated methane derivatives at the surface of $\mathrm{I}_{\mathrm{h}}$ ice by means of grand canonical Monte Carlo simulations under tropospheric conditions. The present study complements our earlier investigations, concerning the adsorption behavior of methane, ${ }^{57}$ fluorinated methane derivatives, ${ }^{56,57}$ and $\mathrm{CH}_{2} \mathrm{Cl}_{2} .{ }^{56}$ Our results have revealed that, similarly to $\mathrm{CH}_{2} \mathrm{Cl}_{2},{ }^{56}$ but in a clear contrast with the fluorinated methane derivatives, ${ }^{56,57}$ neither $\mathrm{CHCl}_{3}$ nor $\mathrm{CCl}_{4}$ shows noticeable adsorption at the ice surface. The reason for this lack of adsorption is primarily the strong intermolecular attraction 
acting between these molecules, leading to condensation before even the first adsorption layer could be built up. This strong cohesion is coupled with a rather weak interaction of these molecules with the ice phase, which causes that even traces of the adsorption layer are missing at the point of condensation.

By contrast, a nearly saturated monolayer of $\mathrm{CH}_{3} \mathrm{Cl}$ is built up before condensation of this adsorbate occurs. This is explained by the considerably stronger adsorbate-ice interaction in this case than for the methane derivatives having more chlorine atoms. This relatively strong interaction of $\mathrm{CH}_{3} \mathrm{Cl}$ with the ice phase originates from the fact that adsorbed $\mathrm{CH}_{3} \mathrm{Cl}$ molecules can orient in such a way (i.e., by turning the $\mathrm{Cl}$ atom straight to the vapor phase) that they form three weak, C-H“-.O type hydrogen bonds with the surface waters. Although such a hydrogen bond is certainly weaker than an $\mathrm{OH}$-donated, $\mathrm{O}-\mathrm{H}^{\cdots \cdots} \mathrm{Cl}$ type one, the fact that three of such weak $\mathrm{H}$-bonds can be formed between the adsorbed $\mathrm{CH}_{3} \mathrm{Cl}$ and surface water molecules clearly overcompensates the relative weakness of this H-bond.

From the atmospheric point of view, our results indicate that the ice surface is probably not a good substrate for trapping chlorinated methane derivatives at such low temperatures that are encountered in the UTLS region. Considering the typical concentration of these species in the UTLS region of $0.5 \times 10^{3}-1.5 \times 10^{2} \mu \mathrm{mol} / \mathrm{m}^{3},{ }^{83}$ and estimating their $p_{0}$ values using the Antoine equation to be in the range of $10^{1}-10^{3} \mathrm{~Pa}$ at $200 \mathrm{~K}$, the atmospherically relevant range of their chemical potential turns out to be around $-60 \mathrm{~kJ} / \mathrm{mol}$. Although the concentration of these molecules can locally exceed their average concentration by several orders of magnitude, it is clear that, from the atmospheric point of view, only the isolated chlorinated methane derivative molecules being adsorbed at the ice surface are of relevance. On the other hand, as these molecules can catalyze various chemical reactions, such as ozone destruction in the troposphere, their atmospheric impact does not require their presence in high concentration. In this respect, it is important to emphasize that, similarly to the fluorinated methane derivatives, ${ }^{59}$ also the chlorinated molecules prefer orientations at the ice surface in which at least one of their halogen atoms is exposed to the gas phase, making it easily releasable upon photodissociation processes as well as available for reactions with other gas phase molecules. 


\section{Acknowledgements}

This project is supported by the Hungarian OTKA Foundation under project No. 119732, by the Hungarian-French Intergovernmental Science and Technology Program (BALATON) under project No. TéT_15_FR-1-2016-0056, and by CNRS in the framework of an international program for scientific cooperation (PICS).

\section{References}

(1) Molina, M.; Tso, T. L; Molina, L. T.; Wang, F .C. Y. Antarctic Stratospheric Chemistry of Chlorine Nitrate, Hydrogen Chloride, and Ice: Release of Active Chlorine. Science 1987, 238, 1253-1257.

(2) Simpson, W. R.; von Glasow, R.; Riedel, K.; Anderson, P.; Ariya, P.; Bottenheim, J.; Burrows, J.; Carpenter, L. J.; Frieß, U.; Goodsite, M. E.; et al. Halogens and their Role in Polar Boundary Layer Ozone Depletion. Atmos. Chem. Phys. 2007, 7, 4375-4418.

(3) Laurence, M. G.; Crutzen, P. J. The Impact of Cloud Particle Gravitational Settling on Soluble Trace Gas Distributions. Tellus 1998, 50B, 263-289.

(4) Lei, Y. D.; Wania, F. Is Rain or Snow a More Efficient Scavenger of Organic Chemicals? Atmos. Environ. 2004, 38, 3557-3571.

(5) Robinson, D. A.; Dewey, K. F.; Heim Jr., R. R. Global Snow Cover Monitoring: An Update. Bull. Am. Meteorol. Soc. 1993, 74, 1689-1696.

(6) Dominé, F.; Shepson, P. B. Air-Snow Interactions and Atmospheric Chemistry. Science 2002, 297, 1506-1510.

(7) Grannas, A. M.; Jones, A. E.; Dibb, J.; Ammann, M.; Anastasio, C.; Beine, H. J.; Bergin, M.; Bottenheim, J.; Boxe, C. S.; Carver, G.; et al. An Overview of Snow Photochemistry: Evidence, Mechanisms and Impacts. Atmos. Chem. Phys. 2007, 7, 4329-4373.

(8) Abbatt, J .P. D. Interactions of Atmospheric Trace Gases with Ice Surfaces: Adsorption and Reaction. Chem. Rev. 2003, 103, 4783-4800.

(9) Huthwelker, T.; Ammann, M.; Peter, T. The Uptake of Acidic Gases on Ice. Chem. Rev. 2006, 106, 1375-1444. 
(10) Bartels-Rausch, T.; Jacobi, H. W.; Kahan, T. F.; Thomas, J. L.; Thomson, E. S.; Abbatt, J. P. D.; Ammann, M.; Blackford, J. R.; Bluhm; H.; Boxe. C.; et al. A Review of AirIce Chemical and Physical Interactions (AICI): Liquids, Quasi-Liquids, and Solids in Snow. Atmos. Chem. Phys. 2014, 14, 1587-1633.

(11) Crowley, J. N.; Ammann, M., Cox, R. A.; Hynes, R. G.; Jenkin, M. E.; Mellouki, A.; Rossi, M. J.; Troe, J.; Wallington, T. J. Evaluated Kinetic and Photochemical Data for Atmospheric Chemistry: Volume V - Heterogeneous Reactions on Solid Substrates. Atmos. Chem. Phys. 2010, 10, 9059-9223.

(12) Abbatt, J. P. D.; Thomas, J. L.; Abrahamsson, K.; Boxe, C.; Granfors, A.; Jones, A. E.; King, M. D.; Saiz-Lopez, A.; Shepson, P. B.; Sodeau, J.; et al. Halogen Activation via Interactions With Environmental Ice and Snow in the Polar Lower Troposphere and Other Regions. Atmos. Chem. Phys. 2012, 12, 6237-6271.

(13) Velders, G. J. M.; Fahey, D. W.; Daniel, J. S.; McFarland, M.; Andersen, O. The Large Contribution of Projected HFC Emissions to Future Climate Forcing. Proc. Natl. Acad. Sci. U.S.A. 2009, 106, 10949-10954.

(14) Blanchard, J.; Roberts, J. T. Interaction of $\mathrm{CCl}_{4}$ with the Surface of Amorphous Ice. Langmuir 1994, 10, 3303-3310.

(15) Sadtchenko, V.; Knutsen, K.; Giese, C. F.; Ronald Gentry, W. Interactions of $\mathrm{CCl}_{4}$ with Thin $\mathrm{D}_{2} \mathrm{O}$ Amorphous Ice Films. Part I. A Nanoscale Probe of Ice Morphology. J. Phys. Chem. B 2000, 104, 2511-2521.

(16) Sadtchenko, V.; Knutsen, K.; Giese, C. F.; Ronald Gentry, W. Interactions of $\mathrm{CCl}_{4}$ with Thin $\mathrm{D}_{2} \mathrm{O}$ Amorphous Ice Films.2. Variations of Desorption Kinetics with Ice Preparation Conditions and Evidence for Distinct Strutures of Low-Density Amorphous Ice. J. Phys. Chem. B 2000, 104, 4894-4902.

(17) Holmes, N. S.; Sodeau, J. R. A Study of the Interaction between Halomethanes and Water-Ice. J. Phys. Chem. A 1999, 103, 4673-4679.

(18) Schaff, J. E.; Roberts, J. T. Adsorbed States of Acetonitrile and Chloroform on Amorphous and Crystalline Ice Studied with X-Ray Photoelectron Spectroscopy. Surf. Sci. 1999, 426, 384-394.

(19) Grecea, M. L.; Backus, E. H. G.; Fraser, H. J.; Pradeep, T.; Kleyn, A. W.; Bonn, M. Mobility of Haloforms on Ice Surfaces. Chem. Phys. Lett. 2004, 385, 244-248. 
(20) Pysanenko, A.; Habartová, A. Svrčková, P.; Lengyel, J.; Poterya, V.; Roeselová, M.; Fedor, J.; Fárnik, M. Lack of Aggregation of Molecules on Ice Nanoparticles. J. Phys. Chem. A 2015, 119, 8991-8999.

(21) Aoki, M.; Ohashi, Y.; Masuda, S. Interactions of $\mathrm{CHCl}_{3}$ Molecules with a Crystalline Ice Grown on Pt(111) Studied by Metastable Impact Electron Spectroscopy. Surf. Sci. 2003, 532-535, 137-141.

(22) Cyriac, J.; Pradeep, T. Probing Difference in Diffusivity of Chloromethanes Through Water Ice in the Temperature Range of 110-150 K. J. Phys. Chem. 2007, 111, 85578565.

(23) Vysokikh, T. A.; Mukhamedzyanova, D. F.; Yagodovskaya, T. V.; Savilov, S. V.; Lunin, V. V. The Interaction of $\mathrm{CH}_{3} \mathrm{Cl}, \mathrm{CH}_{2} \mathrm{Cl}_{2}, \mathrm{CHCl}_{3}$, and $\mathrm{CCl}_{4}$ with Ozone on the Surface of Ice under Stratospheric Conditions. Russian J. Phys. Chem. A 2007, 81, 1836-1839.

(24) Adams, D. J. Grand Canonical Ensemble Monte Carlo for a Lennard-Jones Fluid. Mol. Phys. 1975, 29, 307-311.

(25) Allen, M. P.; Tildesley, D. J. Computer Simulation of Liquids; Clarendon: Oxford, 1987.

(26) Rutkai, G.; Kristóf, T. Molecular Simulation Study of Intercalation of Small Molecules in Kaolinite. Chem. Phys. Letters 2008, 462, 269-274.

(27) Croteau, T.; Bertram, A. K.; Patey, G. N. Adsorption and Structure of Water on Kaolinite Surfaces: Possible Insight into Ice Nucleation from Grand Canonical Monte Carlo Calculations. J. Phys. Chem. A 2008, 112, 10708-10712.

(28) Jameson, C. J.; Jameson, K.; Baello, B. I.; Lim, H. M. Grand Canonical Monte Carlo Simulations of the Distribution and Chemical Shifts of Xenon in the Cages of Zeolite NaA. 1. Distribution and Xe-129 Chemical Shifts. J. Chem. Phys. 1994, 100, 59655976.

(29) Jameson, C. J.; Jameson, K.; Lim, H. M.; Baello, B. I. Grand Canonical Monte Carlo Simulations of the Distribution and Chemical Shifts of Xenon in the Cages of Zeolite NaA. 2. Structure of the Adsorbed Fluid. J. Chem. Phys. 1994, 100, 5977-5987.

(30) Smit, B. Grand Canonical Monte Carlo Simulations of Chain Molecules: Adsorption Isotherms of Alkanes in Zeolites. Mol. Phys. 1995, 85, 153-172. 
(31) Pellenq, R. J. M.; Tavitian, B.; Espinat, D.; Fuchs, A. H. Grand Canonical Monte Carlo Simulations of Adsorption of Polar and Nonpolar Molecules in NaY Zeolite. Langmuir 1996, 12, 4768-4783.

(32) Macedonia, M. D.; Maginn, E. J. Pure and Binary Component Sorption Equilibria of Light Hydrocarbons in the Zeolite Silicalite from Grand Canonical Monte Carlo Simulations. Fluid Phase Equil. 1999, 158-160, 19-27.

(33) Rutkai, G.; Csányi, É.; Kristóf, T. Prediction of Adsorption Equilibria of WaterMethanol Mixtures in Zeolite NaA by Molecular Simulation. Mol. Simul. 2006, 32, 869-875.

(34) Kristóf, T.; Csányi, É.; Rutkai, G. Prediction of Adsorption and Separation of WaterAlcohol Mixtures with Zeolite NaA. Microporous Mesoporous Mat. 2008, 114, 455464.

(35) Puibasset, J.; Pellenq, R. J. M. Water Adsorption on Hydrophilic Mesoporous and Place Silica Substrates: a Grand Canonical Monte Carlo Simulation Study. J. Chem. Phys. 2003, $118,5613-5622$.

(36) Puibasset, J.; Pellenq, R. J. M. Water Adsorption in Disordered Mesoporous Silica (Vycor) at $300 \mathrm{~K}$ and $650 \mathrm{~K}$ : A Grand Canonical Monte Carlo Simulation Study of Hysteresis. J. Chem. Phys. 2005, 122, 094704-1-10.

(37) Daub, C. D.; Patey G. N.; Jack, D. B.; Sallabi A. K. Monte Carlo Simulations of the Adsorption of $\mathrm{CO}_{2}$ on the $\mathrm{MgO}(100)$ Surface. J. Chem. Phys. 2006, 124, 114706-1-9.

(38) Tombácz, E.; Hajdú, A.; Illés, E.; László, K.; Garberoglio, G.; Jedlovszky, P. Water in Contact with Magnetite Nanoparticles, as Seen from Experiments and Computer Simulations. Langmuir 2009, 25, 13007-13014.

(39) Samios, S.; Stubos, A. K.; Kanellopoulos, N. K.; Cracknell, R. F.; Papadopoulos, G. K.; Nicholson, D. Determination of Micropore Size Distribution from Grand Canonical Monte Carlo Simulations and Experimental $\mathrm{CO}_{2}$ Isotherm Data. Langmuir 1997, 13, 2795-2802.

(40) Muller, E. A.; Hung, F. R.; Gubbins, K. E. Adsorption of Water Vapor-Methane Mixtures on Activated Carbons. Langmuir 2000, 16, 5418-5424. 
(41) Challa, S. R.; Sholl, D. S.; Johnson, J. K. Adsorption and Separation of Hydrogen Isotopes in Carbon Nanotubes: Multicomponent Grand Canonical Monte Carlo Simulations. J. Chem. Phys. 2002, 116, 814-824.

(42) Striolo, A.; Chialvo, A. A.; Gubbins, K. E.; Cummings, P. T. Water in Carbon Nanotubes: Adsorption Isotherms and Thermodynamic Properties from Molecular Simulation. J. Chem. Phys. 2005, 122, 234712-1-14.

(43) Moulin, F.; Picaud, S.; Hoang, P. N. M.; Jedlovszky, P. Grand Canonical Monte Carlo Simulation of the Adsorption Isotherms of Water Molecules on a Model Soot Particle $J$. Chem. Phys. 2007, 127, 164719-1-11.

(44) Hantal, Gy.; Picaud, S.; Hoang, P. N. M.; Voloshin, V. P.; Medvedev, N. N.; Jedlovszky, P. Water Adsorption Isotherms on Porous Onionlike Carbonaceous Particles. Simulations with the Grand Canonical Monte Carlo Method. J. Chem. Phys. 2010, 133, 144702-1-12.

(45) Firlej, L. ; Kuchta, B. ; Lazarewicz, A. ; Pfeifer, P. Increased $\mathrm{H}_{2}$ Gravimetric Storage Capacity in Truncated Carbon Slit Pores Modeled by Grand Canonical Monte Carlo. Carbon 2013, 53, 208-215.

(46) Jung, D. H.; Kim, D.; Lee, T. B.; Choi, S. B.; Yoon, J. H.; Kim, J.; Choi, K.; Choi, S. H. Grand Canonical Monte Carlo Simulation Study on the Catenation Effect on Hydrogen Adsorption onto the Interpenetrating Metal-Organic Frameworks. J. Phys. Chem. B 2006, 110, 22987-22990.

(47) Garberoglio, G. Computer Simulation of the Adsorption of Light Gases in Covalent Organic Frameworks. Langmuir 2007, 23, 12154-12158.

(48) Ramsahye, N. A.; Maurin, G.; Bourelly, S.; Llewellyn, P. L.; Devic, T.; Serre, C.; Loiseau, T.; Ferey, G. Adsorption of $\mathrm{CO}_{2}$ in Metal Organic Frameworks of Different Metal Centres: Grand Canonical Monte Carlo Simulations Compared to Experiments. Adsorption 2007, 13, 461-467.

(49) Szőri, M.; Jedlovszky, P.; Roeselová, M. Water Adsorption on Hydrophilic and Hydrophobic Self-Assembled Monolayers as Proxies For Atmospheric Surfaces. A Grand Canonical Monte Carlo Simulation Study. Phys. Chem. Chem. Phys. 2010, 12, 4604-4616. 
(50) Szőri, M.; Roeselová, M.; Jedlovszky, P. Surface Hydrophilicity-Dependent Water Adsorption on Mixed Self-Assembled Monolayers of $\mathrm{C}_{7}-\mathrm{CH}_{3}$ and $\mathrm{C}_{7}-\mathrm{COOH}$ residues. A Grand Canonical Monte Carlo Simulation Study. J. Phys. Chem. C 2011, 115, 19165-19177.

(51) Resat, H.; Mezei, M. Grand Canonical Monte Carlo Simulation of Water Positions in Crystal Hydrates. J. Am. Chem. Soc. 1994, 116, 7451-7452.

(52) Jedlovszky, P.; Partay, L.; Hoang, P. N. M.; Picaud, S.; von Hessberg, P.; Crowley, J. N. Determination of the Adsorption Isotherm of Methanol on the Surface of Ice. An Experimental and Grand Canonical Monte Carlo Simulation Study. J. Am. Chem. Soc. 2006, 128, 15300-15309.

(53) Jedlovszky, P.; Hantal, Gy.; Neuróhr, K.; Picaud, S.; Hoang, P. N. M.; von Hessberg, P.; Crowley, J. N. Adsorption Isotherm of Formic Acid on The Surface of Ice, as Seen from Experiments and Grand Canonical Monte Carlo Simulation. J. Phys. Chem. C 2008, 112, 8976-8987.

(54) Darvas, M.; Lasne, J.; Laffon, C.; Parent, P.; Picaud, S.; Jedlovszky, P. Adsorption of Acetaldehyde on Ice as Seen From Computer Simulation and Infrared Spectroscopy Measurements. Langmuir 2012, 28, 4198-4207.

(55) Mészár, Zs. E.; Hantal, Gy.; Picaud, S.; Jedlovszky, P. Adsorption of Aromatic Hydrocarbon Molecules at the Surface of Ice, As Seen by Grand Canonical Monte Carlo Simulation. J. Phys. Chem. C 2013, 117, 6719-6729.

(56) Picaud, S.; Jedlovszky, P. Adsorption of $\mathrm{H}_{2} \mathrm{O}_{2}$ at the Surface of $\mathrm{I}_{h}$ Ice, as Seen from Grand Canonical Monte Carlo Simulations. Chem. Phys. Letters 2014, 600, 73-78.

(57) Szőri, M.; Jedlovszky, P. Adsorption of HCN at the Surface of Ice. A Grand Canonical Monte Carlo Simulation Study. J. Phys. Chem. C 2014, 118, 3599-3609.

(58) Sumi, I.; Picaud, S.; Jedlovszky, P. Adsorption of Methylene Fluoride and Methylene Chloride at the Surface of Ice under Tropospheric Conditions. A Grand Canonical Monte Carlo Simulation Study. J. Phys. Chem. C 2015, 119, 17243-17252.

(59) Sumi, I.; Fábián, B.; Picaud, S.; Jedlovszky, P. Adsorption of Fluorinated Methane Derivatives at the Surface of Ice under Tropospheric Conditions, As Seen from Grand Canonical Monte Carlo Simulations. J. Phys. Chem. C 2016, 120, 17386-17399. 
(60) Szentirmai, V.; Szőri, M.; Picaud, S.; Jedlovszky, P. Adsorption of Methylamine at the Surface of Ice. A Grand Canonical Monte Carlo Simulation Study J. Phys. Chem. C 2016, 120, 23480-23489.

(61) Pártay, L. B.; Jedlovszky, P.; Hoang, P. N. M.; Picaud, S.; Mezei, M. Free-Energy Profile of Small Solute Molecules at the Free Surfaces of Water and Ice, as Determined by Cavity Insertion Widom Calculations. J. Phys. Chem. C 2007, 111, 9407-9416.

(62) Habartová, A.; Valsaraj, K. T.; Roeselová, M. Molecular Dynamics Simulations of Small Halogenated Organics at the Air-Water Interface: Implications in Water Treatment and Atmospheric Chemistry. J. Phys. Chem. A 2013, 1176, 9205-9215.

(63) Habartová, A.; Hormain, L.; Pluhařová, E.; Briquez, S.; Monnerville, M.; Toubin, C.; Roeselová, M. Molecular Simulations of Halomethanes at the Air/Ice Interface. J. Phys. Chem. A 2015, 119, 10052-10059.

(64) Harper, K.; Minofar, B.; Sierra-Hernandez, M. N.; Casillas-Ituarte, N. N.; Roeselova, M.; Allen, H. C. Surface Residence and Uptake of Methyl Chloride and Methyl Alcohol at the Air/Water Interface Studied by Vibrational Sum Frequency Spectroscopy and Molecular Dynamics. J. Phys. Chem. A 2009, 113, 2015-2024.

(65) Wang, J.; Wolf, R. M.; Caldwell, J. W.; Kollman, P. A.; Case, D. A. Development and Testing of a General AMBER Force Field. J. Comp. Chem. 2004, 25, 1157-1174.

(66) Dietz, W.; Heinzinger, K. Structure of Liquid Chloroform. A Comparison between Computer Simulation and Neutron Scattering Results. Ber. Bunsenges. Phys. Chem. 1984, $88,543-546$.

(67) Duffy, E. M.; Severance, D. L.; Jorgensen, W. L. Solvent Effects on the Barrier to Isomerization for a Tertiary Amide from $\mathrm{Ab}$ Initio and Monte Carlo Calculations. $J$. Am. Chem. Soc. 1992, 114, 7535-7542.

(68) Mahoney, M.; Jorgensen, W. L. A Five-Site Model for Liquid Water and the Reproduction of The Density Anomaly by Rigid, Nonpolarizable Potential Functions. J. Chem. Phys. 2000, 112, 8910-8922.

(69) Nada, H.; van der Eerden, J. P. M. J. An Intermolecular Potential Model for the Simulation of Ice and Water Near the Melting Point: A Six-Site Model of $\mathrm{H}_{2} \mathrm{O} . J$. Chem. Phys. 2003, 118, 7401-7413. 
(70) Vega, C.; Sanz, E.; Abascal, J. L. F. The Melting Temperature of the Most Common Models of Water. J. Chem. Phys. 2005, 122, 114507-1-9.

(71) Chandrasekhar, J.; Smith, S. F.; Jorgensen, W. L. Theoretical Examination of the $\mathrm{S}_{\mathrm{N}} 2$ Reaction Involving Chloride Ion and Methyl Chloride in the Gas Phase and Aqueous Solutions. J. Am. Chem. Soc. 1985, 107, 154-163.

(72) Jorgensen, W. L.; Briggs, J. M.; Leonor Contreras, M. Relative partition Coefficients for Organic Solutes from Fluid Simulations. J. Phys. Chem. 1990, 94, 1683-1686.

(73) CRC Handbook of Chemistry and Physics; $63^{\text {rd }}$ Edition, Weast, R. C.; Astle, M. J.; Eds.; CRC Press: Boca Raton, 1982-1983.

(74) Mezei, M. MMC: Monte Carlo Program for Simulation of Molecular Assemblies. URL: http://inka.mssm.edu/ mezei/mmc.

(75) Mezei, M. A Cavity-Biased ( $\mathrm{T}, \mathrm{V}, \mu)$ Monte Carlo Method for the ComputerSimulation of Fluids. Mol. Phys. 1980, 40, 901-906.

(76) Mezei, M. Grand Canonical Ensemble Monte Carlo Study of Dense Liquid LennardJones, Soft Spheres and Water. Mol. Phys. 1987, 61, 565-582. Erratum: 1989, 67, 12071208.

(77) Metropolis, N.; Rosenbluth, A. W.; Rosenbluth, M. N.; Teller, A. H.; Teller, E. Equation of State Calculations by Fast Computing Machines J. Chem. Phys. 1953, 21 1087-1093.

(78) Langmuir, I. The Constitution and Fundamental Properties of Solids and Liquids. Part I: Solids. J. Am. Chem. Soc. 1916, 38, 2221-2295.

(79) Shaw, D. J. Introduction to Colloid and Surface Chemistry, Butterworths: London, 1980.

(80) Jedlovszky, P.; Vincze, Á.; Horvai, G. New Insight into the Orientational Order of Water Molecules at the Water/1,2-Dichloroethane Interface: A Monte Carlo Simulation Study. J. Chem. Phys. 2002, 117, 2271-2280.

(81) Jedlovszky, P.; Vincze, Á.; Horvai, G. Full Description of the Orientational Statistics of Molecules Near to Interfaces. Water at the Interface with $\mathrm{CCl}_{4}$. Phys. Chem. Chem. Phys. 2004, 6, 1874-1879.

(82) Picaud, S.; Hoang, P. N. M. Molecular Dynamics Simulations of Chloroform on Ice. Phys. Chem. Chem. Phys. 2004, 6, 1970-1974. 
(83) Harper, D. B. The Contribution of Natural Halogenation Processes to the Atmospheric Halomethane Burden. In Naturally-Produced Organohalogens; Grimwall, A.; de Leer, E. W. B.; eds.; Springer: Dordrecht, 1995, pp. 21-33. 


\section{Tables}

Table 1. Data of the Adsorption Isotherm of $\mathrm{CH}_{3} \mathrm{Cl}$ on Ice

\begin{tabular}{|c|c|c|c|}
\hline $\bar{c} \mu / \mathrm{kJ} \mathrm{mol}^{-1}$ & $\langle N\rangle$ & $p / p_{0}$ & 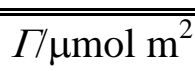 \\
\hline-61.69 & 0.0006 & $2.32 \times 10^{-7}$ & $3.57 \times 10^{-5}$ \\
\hline-60.02 & 0.0019 & $6.32 \times 10^{-7}$ & $1.13 \times 10^{-4}$ \\
\hline-58.36 & 0.0050 & $1.72 \times 10^{-6}$ & $2.97 \times 10^{-4}$ \\
\hline-56.70 & 0.0140 & $4.67 \times 10^{-6}$ & $8.32 \times 10^{-4}$ \\
\hline-55.04 & 0.0344 & $1.27 \times 10^{-5}$ & $2.04 \times 10^{-3}$ \\
\hline-53.37 & 0.0924 & $3.45 \times 10^{-5}$ & $5.49 \times 10^{-3}$ \\
\hline-51.71 & 0.2740 & $9.37 \times 10^{-5}$ & $1.63 \times 10^{-2}$ \\
\hline-50.05 & 0.6309 & $2.55 \times 10^{-4}$ & $3.75 \times 10^{-2}$ \\
\hline-48.38 & 1.454 & $6.93 \times 10^{-4}$ & $8.64 \times 10^{-2}$ \\
\hline-47.55 & 1.946 & $1.14 \times 10^{-3}$ & 0.116 \\
\hline-46.72 & 2.408 & $1.88 \times 10^{-3}$ & 0.143 \\
\hline$-45.89^{a}$ & 4.236 & $3.10 \times 10^{-3}$ & 0.252 \\
\hline-45.06 & 5.827 & $5.12 \times 10^{-3}$ & 0.346 \\
\hline-44.23 & 7.871 & $8.44 \times 10^{-3}$ & 0.468 \\
\hline-43.40 & 10.09 & $1.39 \times 10^{-2}$ & 0.600 \\
\hline-42.56 & 12.32 & $2.29 \times 10^{-2}$ & 0.732 \\
\hline-41.73 & 17.07 & $3.78 \times 10^{-2}$ & 1.02 \\
\hline-40.90 & 25.53 & $6.23 \times 10^{-2}$ & 1.52 \\
\hline-40.07 & 34.90 & 0.103 & 2.07 \\
\hline$-39.24^{\mathrm{a}}$ & 47.53 & 0.169 & 2.83 \\
\hline-38.41 & 65.45 & 0.279 & 3.89 \\
\hline-37.58 & 88.87 & 0.461 & 5.28 \\
\hline-36.75 & 116.0 & 0.760 & 6.90 \\
\hline$-36.41^{a}$ & 130.7 & 0.928 & 7.77 \\
\hline-36.33 & 134.6 & 0.975 & 8.00 \\
\hline-36.25 & 638.0 & & \\
\hline-36.16 & 668.9 & & \\
\hline$-36.08^{a}$ & 668.7 & & \\
\hline-35.75 & 671.2 & & \\
\hline-35.08 & 674.7 & & \\
\hline-33.42 & 690.5 & & \\
\hline-31.76 & 703.5 & & \\
\hline
\end{tabular}

${ }^{\mathrm{a}} 2500$ sample configurations have been saved for detailed analyses at these chemical potentials 
Table 2. Data of the Adsorption Isotherm of $\mathrm{CHCl}_{3}$ on Ice

\begin{tabular}{|c|c|c|c|}
\hline$\mu / \mathrm{kJ} \mathrm{mol}^{-1}$ & $\langle N\rangle$ & $p / p_{0}$ & $\Pi / \mu \mathrm{mol} \mathrm{m}{ }^{2}$ \\
\hline-47.21 & 0.0057 & $3.61 \times 10^{-3}$ & $3.39 \times 10^{-4}$ \\
\hline-46.38 & 0.0098 & $5.95 \times 10^{-3}$ & $5.82 \times 10^{-4}$ \\
\hline-45.54 & 0.0156 & $9.80 \times 10^{-3}$ & $9.27 \times 10^{-4}$ \\
\hline-44.71 & 0.0260 & $1.62 \times 10^{-2}$ & $1.55 \times 10^{-3}$ \\
\hline-43.88 & 0.0437 & $2.67 \times 10^{-2}$ & $2.60 \times 10^{-3}$ \\
\hline-43.05 & 0.0690 & $4.39 \times 10^{-2}$ & $4.10 \times 10^{-3}$ \\
\hline-42.22 & 0.118 & $7.24 \times 10^{-2}$ & $7.04 \times 10^{-3}$ \\
\hline-41.39 & 0.199 & 0.119 & $1.18 \times 10^{-2}$ \\
\hline-40.56 & 0.334 & 0.197 & $1.98 \times 10^{-2}$ \\
\hline-39.73 & 0.552 & 0.325 & $3.28 \times 10^{-2}$ \\
\hline-38.89 & 0.932 & 0.535 & $5.54 \times 10^{-2}$ \\
\hline-38.73 & 1.121 & 0.592 & $6.66 \times 10^{-2}$ \\
\hline-38.56 & 1.335 & 0.654 & $7.94 \times 10^{-2}$ \\
\hline-38.39 & 1.468 & 0.723 & $8.72 \times 10^{-2}$ \\
\hline-38.23 & 1.751 & 0.799 & 0.104 \\
\hline-38.06 & 1.999 & 0.883 & 0.119 \\
\hline$-37.90^{\mathrm{a}}$ & 2.522 & 0.975 & 0.150 \\
\hline-37.81 & 406.3 & & \\
\hline$-37.73^{a}$ & 406.1 & & \\
\hline-37.56 & 406.9 & & \\
\hline-37.40 & 404.3 & & \\
\hline-37.23 & 406.4 & & \\
\hline-36.40 & 406.0 & & \\
\hline-35.57 & 406.5 & & \\
\hline-33.91 & 408.2 & & \\
\hline-32.24 & 408.1 & & \\
\hline-30.58 & 408.1 & & \\
\hline
\end{tabular}

"a2500 sample configurations have been saved for detailed analyses at these chemical potentials 
Table 3. Data of the Adsorption Isotherm of $\mathrm{CCl}_{4}$ on Ice

\begin{tabular}{|c|c|c|c|}
\hline$\mu / \mathrm{kJ} \mathrm{mol}^{-1}$ & $\langle N\rangle$ & $p / p_{0}$ & $\bar{l} \Pi \mu \mathrm{mol} \mathrm{m}{ }^{2}$ \\
\hline-51.17 & 0.0001 & $1.40 \times 10^{-4}$ & $5.94 \times 10^{-6}$ \\
\hline-49.50 & 0.0003 & $3.80 \times 10^{-4}$ & $1.78 \times 10^{-5}$ \\
\hline-47.84 & 0.0006 & $1.03 \times 10^{-3}$ & $3.57 \times 10^{-5}$ \\
\hline-46.18 & 0.0017 & $2.81 \times 10^{-3}$ & $1.01 \times 10^{-4}$ \\
\hline-44.51 & 0.0044 & $7.64 \times 10^{-3}$ & $2.61 \times 10^{-4}$ \\
\hline-42.85 & 0.0118 & $2.08 \times 10^{-2}$ & $7.01 \times 10^{-4}$ \\
\hline-41.19 & 0.0394 & $5.64 \times 10^{-2}$ & $2.34 \times 10^{-3}$ \\
\hline-39.53 & 0.0918 & 0.153 & $5.46 \times 10^{-3}$ \\
\hline-37.86 & 0.264 & 0.417 & $1.57 \times 10^{-2}$ \\
\hline-37.36 & 0.359 & 0.563 & $2.13 \times 10^{-2}$ \\
\hline-37.20 & 0.411 & 0.622 & $2.44 \times 10^{-2}$ \\
\hline-37.03 & 0.456 & 0.687 & $2.71 \times 10^{-2}$ \\
\hline-36.87 & 0.501 & 0.760 & $2.98 \times 10^{-2}$ \\
\hline-36.70 & 0.563 & 0.839 & $3.34 \times 10^{-2}$ \\
\hline-36.53 & 0.665 & 0.928 & $3.95 \times 10^{-2}$ \\
\hline-36.45 & 0.703 & 0.975 & $4.18 \times 10^{-2}$ \\
\hline-36.37 & 326.6 & & \\
\hline-36.20 & 323.0 & & \\
\hline-34.54 & 324.5 & & \\
\hline-32.87 & 327.0 & & \\
\hline-31.21 & 327.4 & & \\
\hline
\end{tabular}


Table 4. Interaction Parameters of the Molecular Models Used ${ }^{\mathrm{a}}$

\begin{tabular}{ccccc}
\hline \hline Molecule & Site & $\sigma / \AA$ & $\varepsilon / \mathrm{kJ} \mathrm{mol}^{-1}$ & $q / \mathrm{e}$ \\
\hline \multirow{2}{*}{$\mathrm{CH}_{3} \mathrm{Cl}^{\mathrm{b}}$} & $\mathrm{C}$ & 3.40 & 0.460 & -0.442 \\
& $\mathrm{H}$ & 2.50 & 0.070 & 0.238 \\
& $\mathrm{Cl}$ & 3.50 & 1.110 & -0.272 \\
$\mathrm{CHCl}_{3}{ }^{\mathrm{c}}$ & $\mathrm{C}$ & 3.40 & 0.424 & 0.179 \\
& $\mathrm{H}$ & 2.20 & 0.083 & 0.082 \\
& $\mathrm{Cl}$ & 3.44 & 1.248 & -0.087 \\
$\mathrm{CCl}_{4}{ }^{\mathrm{d}}$ & $\mathrm{C}$ & 3.80 & 0.208 & 0.248 \\
& $\mathrm{Cl}$ & 3.47 & 1.109 & -0.062 \\
& $\mathrm{O}$ & 3.12 & 0.670 & 0.000 \\
Water $^{\mathrm{e}}$ & $\mathrm{H}$ & - & - & 0.241 \\
& $\mathrm{~L}$ & - & - & -0.241 \\
\hline
\end{tabular}

${ }^{\mathrm{a}} \sigma, \varepsilon$ and $q$ stand for the Lennard-Jones distance and energy parameters and for the fractional charges, respectively.

${ }^{\mathrm{b}} \mathrm{GAFF}$ force field, Lennard-Jones parameters are taken from Ref. 65, fractional charges from Ref. 62.

${ }^{\mathrm{c}}$ Ref. 66.

dOPLS model, Ref. 67.

'TIP5P model, Ref. 68.

${ }^{\mathrm{f}}$ Non-atomic interaction site. 
Table 5. Geometry Parameters of the Potential Models Used

\begin{tabular}{|c|c|c|c|c|}
\hline molecule & bond & bond length $(\AA)$ & angle & bond angle (deg) \\
\hline \multirow{3}{*}{$\mathrm{CH}_{3} \mathrm{Cl}$} & $\mathrm{C}-\mathrm{H}$ & 1.090 & & \\
\hline & $\mathrm{C}-\mathrm{Cl}$ & 1.800 & & \\
\hline & & & $\mathrm{H}-\mathrm{C}-\mathrm{Cl}$ & 108.72 \\
\hline \multirow{3}{*}{$\mathrm{CHCl}_{3}$} & $\mathrm{C}-\mathrm{H}$ & 1.100 & & \\
\hline & $\mathrm{C}-\mathrm{Cl}$ & 1.785 & & \\
\hline & & & $\mathrm{H}-\mathrm{C}-\mathrm{Cl}$ & 107.58 \\
\hline \multirow{2}{*}{$\mathrm{CCl}_{4}$} & $\mathrm{C}-\mathrm{Cl}$ & 1.769 & & \\
\hline & & & F-C-F & 109.47 \\
\hline \multirow{4}{*}{$\mathrm{H}_{2} \mathrm{O}$} & $\mathrm{O}-\mathrm{H}$ & 0.957 & & \\
\hline & O-L & 0.700 & & \\
\hline & & & $\mathrm{H}-\mathrm{O}-\mathrm{H}$ & 104.50 \\
\hline & & & L-O-L & 110.70 \\
\hline
\end{tabular}




\section{Figures Legend}

Figure 1. Average number of adsorbate molecules in the basic simulation box as a function of their chemical potential, as obtained in the present work for $\mathrm{CH}_{3} \mathrm{Cl}$ (red circles), $\mathrm{CHCl}_{3}$ (blue down triangles) and $\mathrm{CCl}_{4}$ (orange diamonds). For comparison, results obtained previously for $\mathrm{CH}_{4}$ (Ref. 59, black squares) and $\mathrm{CH}_{2} \mathrm{Cl}_{2}$ (Ref. 58, green up triangles) are also shown. The lines connecting the points serve just as guides to the eye. The arrows indicate the systems that have been used for detailed orientational and energetic analyses (see the text). The inset shows the comparison of the $\langle N\rangle$ vs. $\mu$ data of $\mathrm{CH}_{3} \mathrm{Cl}$ as obtained with the GAFF (Ref. 65, filled circles) and OPLS (Ref. 71, open circles) force fields.

Figure 2. Equilibrium snapshots (side view) of the systems with $\mathrm{CH}_{3} \mathrm{Cl}$ at four different chemical potentials (top row), with $\mathrm{CHCl}_{3}$ at two different chemical potentials (bottom left) and with $\mathrm{CCl}_{4}$ at two different chemical potentials (bottom right). Only the upper half of the basic simulation box is shown in every case. Oxygen, hydrogen, carbon, and chlorine atoms are shown by red, white, grey, and green colors, respectively.

Figure 3. Adsorption isotherm (in the form of surface excess vs. relative pressure) of $\mathrm{CH}_{3} \mathrm{Cl}$ (red circles), $\mathrm{CHCl}_{3}$ (blue down triangles) and $\mathrm{CCl}_{4}$ (orange diamonds) on ice, as obtained from our simulations. For comparison, the isotherms obtained previously for $\mathrm{CH}_{4}$ (Ref. 59, black squares) and $\mathrm{CH}_{2} \mathrm{Cl}_{2}$ (Ref. 58, green up triangles) are also shown. The inset shows the isotherms of $\mathrm{CH}_{2} \mathrm{Cl}_{2}, \mathrm{CHCl}_{3}$, and $\mathrm{CCl}_{4}$ on a magnified scale. The arrows indicate the systems that have been used for detailed orientational and energetic analyses (see the text). 
Figure 4. Number density profile of (a) $\mathrm{CH}_{3} \mathrm{Cl}$ at four selected chemical potential values, and (b) $\mathrm{CHCl}_{3}$ at two selected chemical potential values at the surface of ice along the surface normal axis, $X$. Number density profile of the water molecules in the outmost layer of the ice phase is also shown (black short dashed line). The dashed black vertical lines mark the outer boundary of the first molecular layer (see the text). The inset shows the water number density profile across the entire ice phase. All profiles shown are averaged over the two surfaces in the basic box.

Figure 5. Definition of the local Cartesian frame fixed to the individual $\mathrm{CXY}_{3}$ molecules, and of the polar angles $\vartheta$ and $\phi$ of the surface normal axis, $\underline{X}$, pointing, by our convention, away from the ice phase, in this frame.

Figure 6. $P(\cos \vartheta, \phi)$ orientational maps of the molecules belonging to the first molecular layer at the ice surface at four different chemical potential values for $\mathrm{CH}_{3} \mathrm{Cl}$ (top row), and at two different chemical potential values for $\mathrm{CHCl}_{3}$ (bottom left and right). Lighter shades of grey correspond to higher probabilities (see the grayscale). The orientations preferred by the adsorbed molecules are also illustrated (bottom middle). $\underline{X}$ is the surface normal axis, pointing away from the ice phase. Color coding of the atoms is the same as in Fig. 2.

Figure 7. Distributions of the interaction energy of (a) the $\mathrm{CH}_{3} \mathrm{Cl}$, and (b) the $\mathrm{CHCl}_{3}$ molecules belonging to the first molecular layer at the ice surface with the rest of the system (bottom panels), with the other adsorbate molecules (middle panels) and with the ice phase (top panels). The distributions are shown at four and two different chemical potential values for $\mathrm{CH}_{3} \mathrm{Cl}$ and $\mathrm{CHCl}_{3}$, respectively. 
Figure 1

Sumi et al.

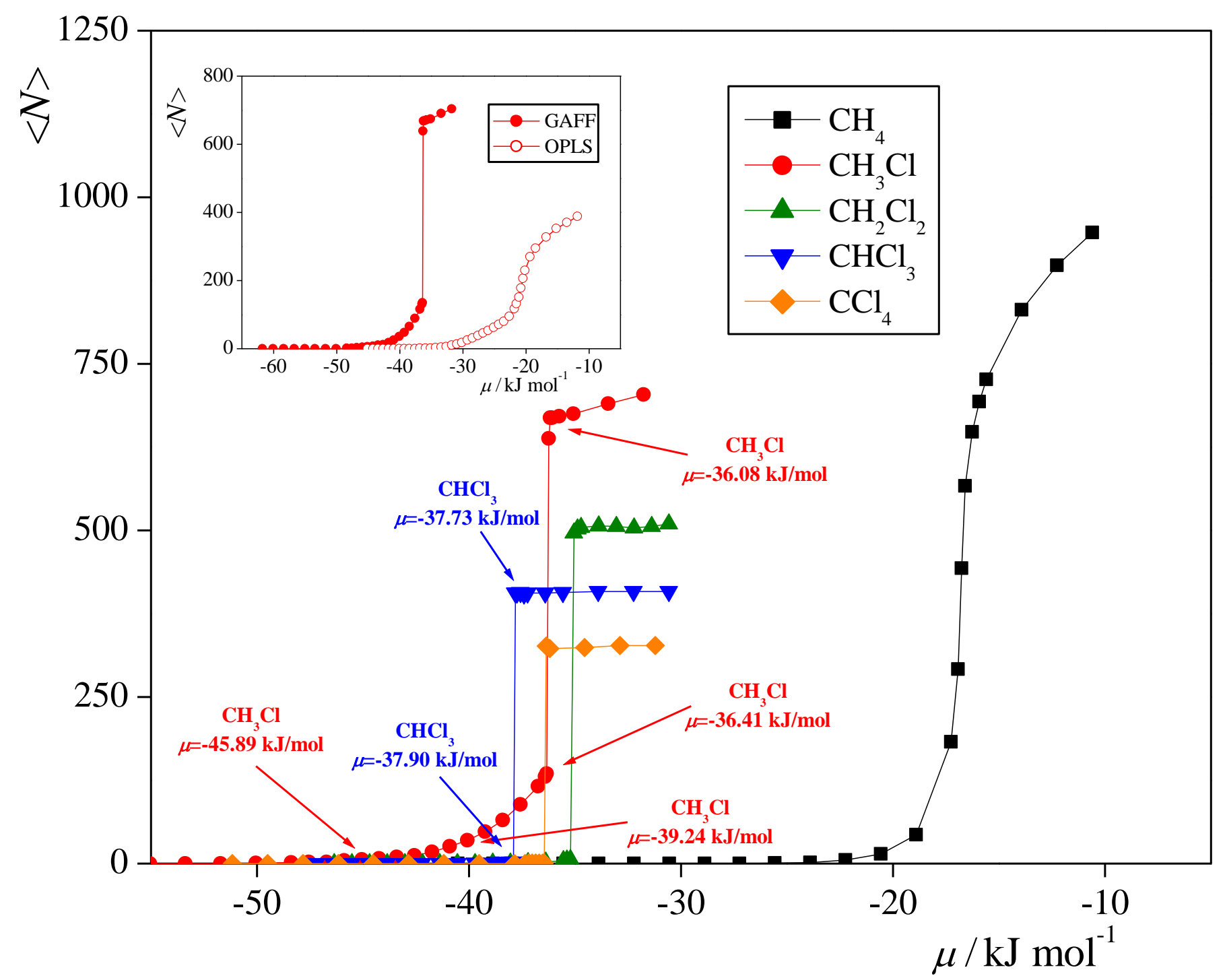


Figure 2

Sumi et al.

\section{$\mathrm{CH}_{3} \mathrm{Cl}$}

$\mu=-45.89 \mathrm{~kJ} / \mathrm{mol}$

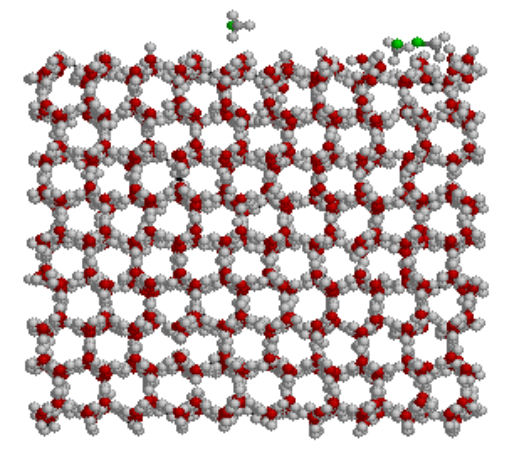

$\mathrm{CHCl}_{3}$

$\mu=-37.90 \mathrm{~kJ} / \mathrm{mol}$

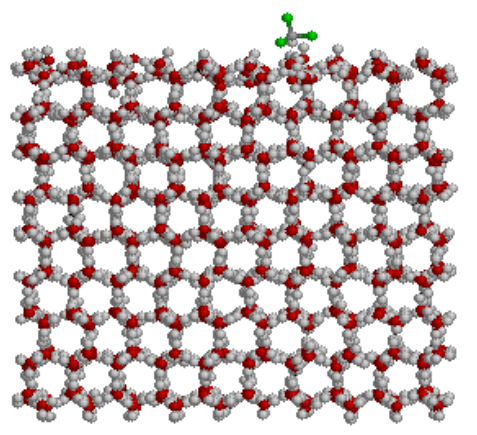

$\mathrm{CH}_{3} \mathrm{Cl}$

$\mu=-39.24 \mathrm{~kJ} / \mathrm{mol}$

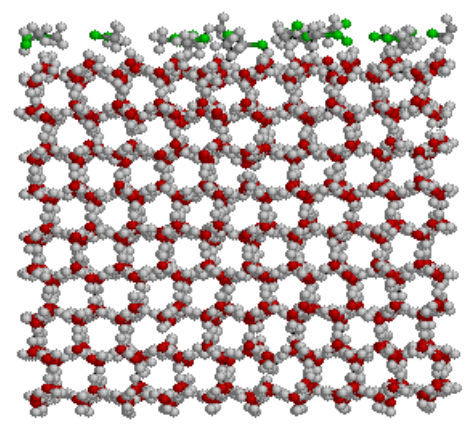

$\mathrm{CHCl}_{3}$

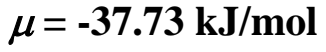

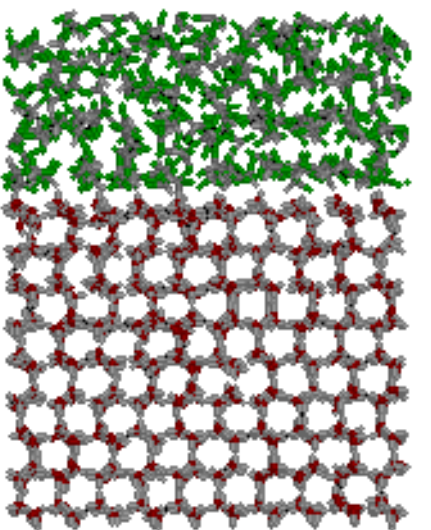

$\mathrm{CH}_{3} \mathrm{Cl}$

$\mu=-\mathbf{3 6 . 4 1} \mathrm{kJ} / \mathrm{mol}$

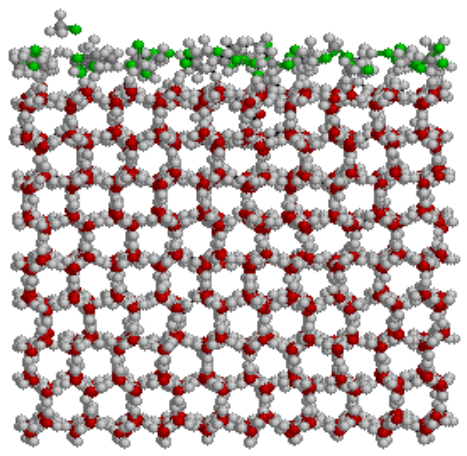

$\mathrm{CCl}_{4}$

$$
\mu=-\mathbf{3 6 . 8 7} \mathrm{kJ} / \mathbf{m o l}
$$

to

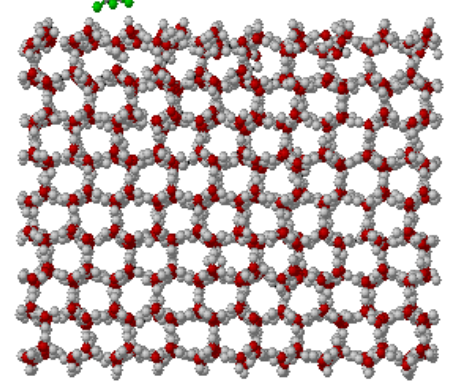

$\mathrm{CH}_{3} \mathrm{Cl}$

$\mu=-\mathbf{3 6 . 0 8} \mathrm{kJ} / \mathrm{mol}$

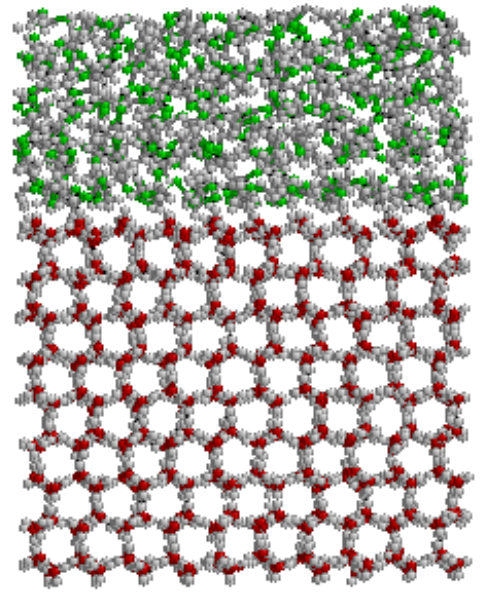

$\mathrm{CCl}_{4}$

$\mu=-\mathbf{3 6 . 3 7} \mathrm{kJ} / \mathbf{m o l}$

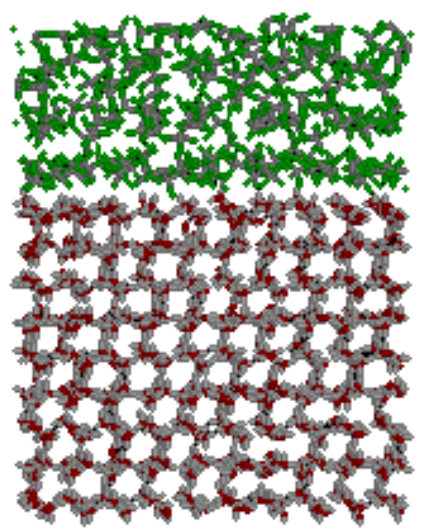


Figure 3

Sumi et al.

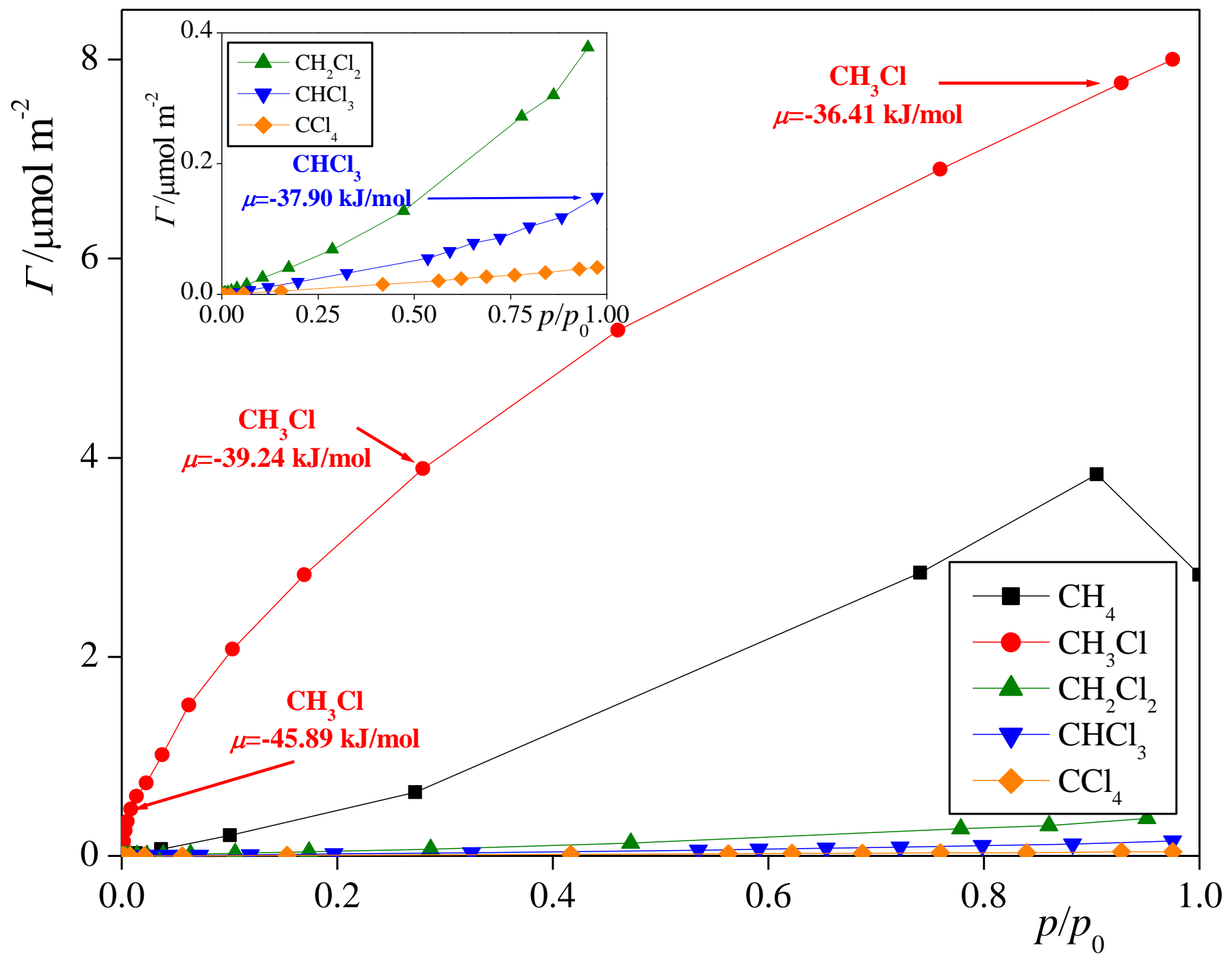


Figure 4

Sumi et al.

(a)

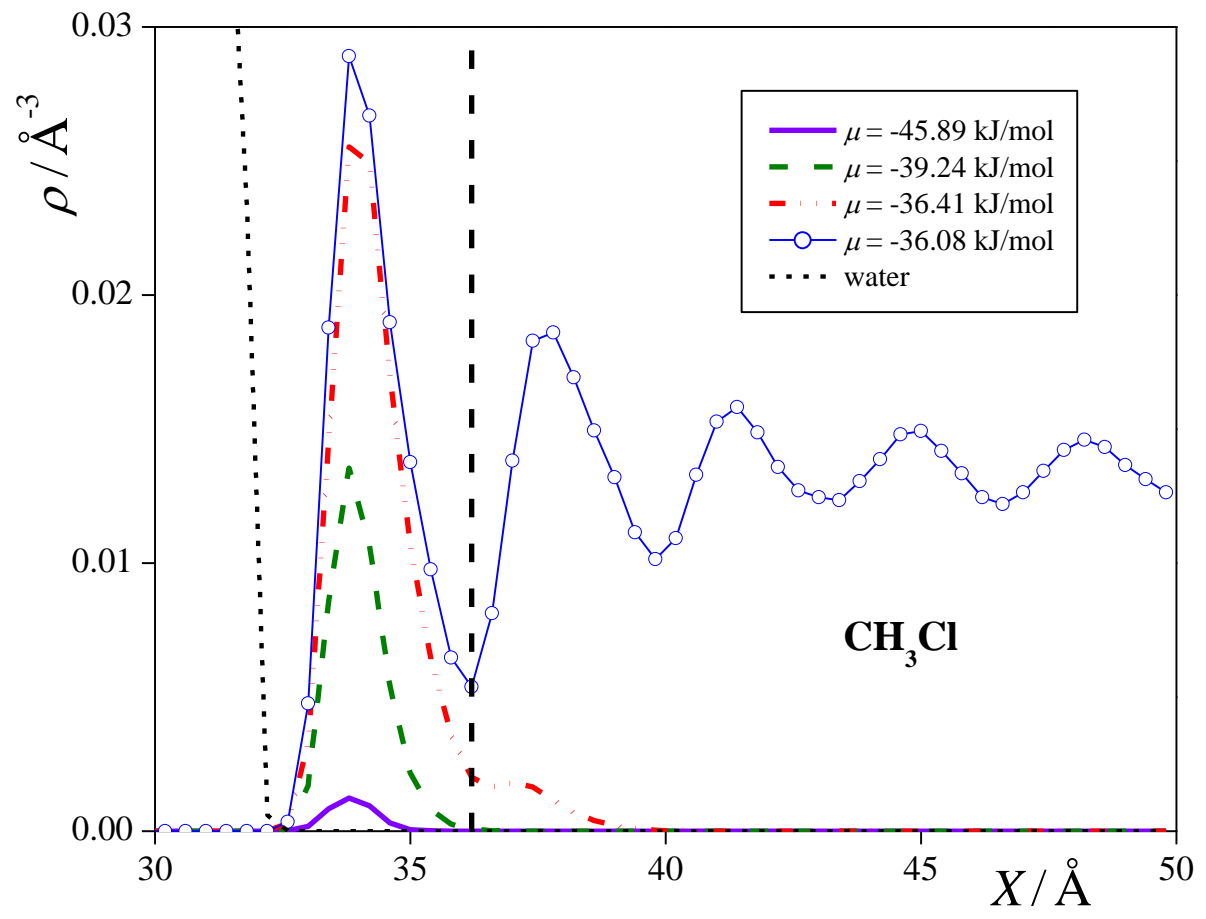

(b)

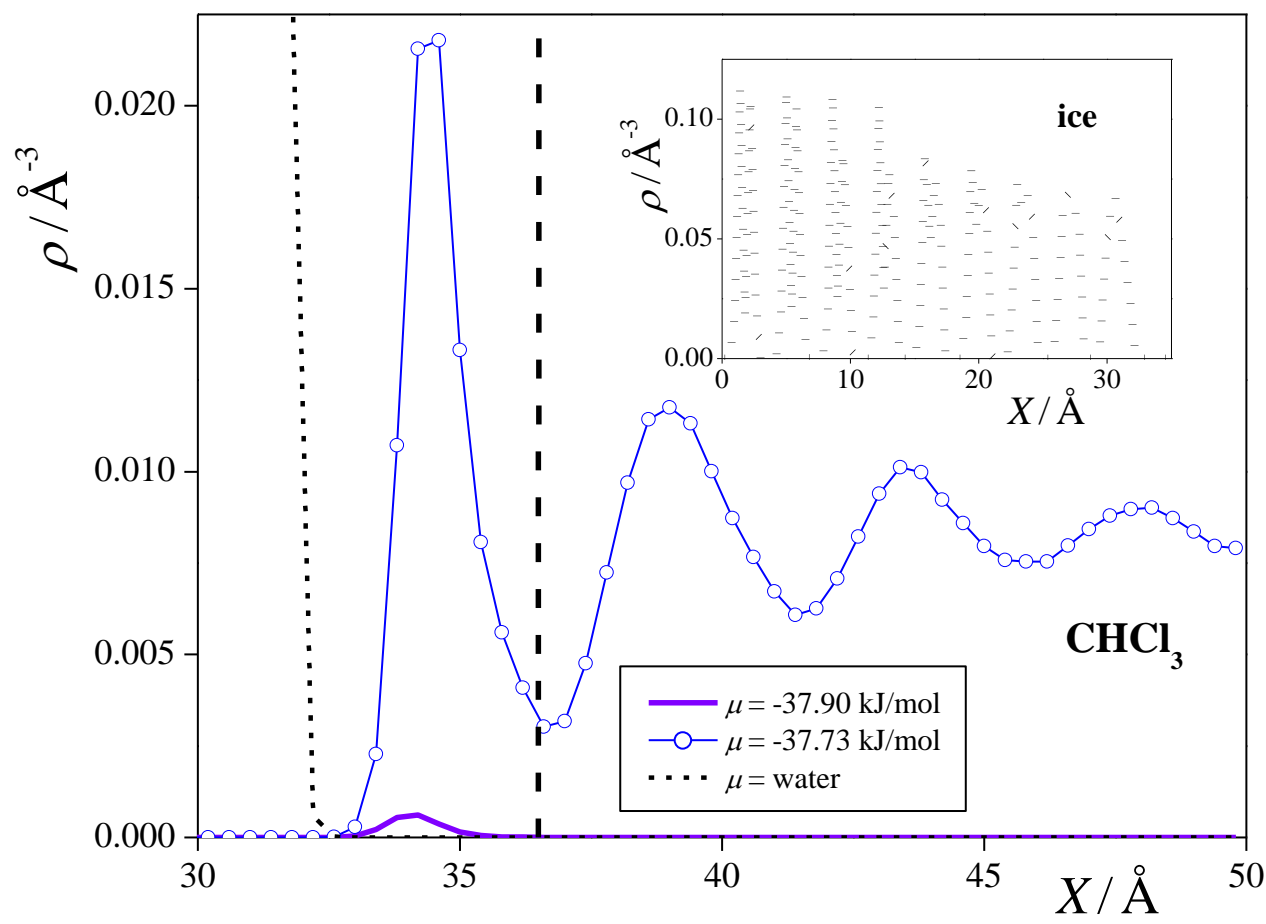


Figure 5

Sumi et al.

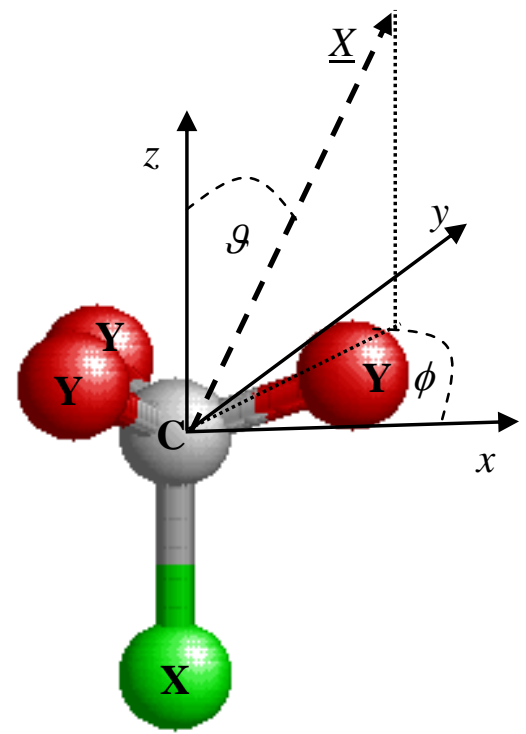


Figure 6

Sumi et al.
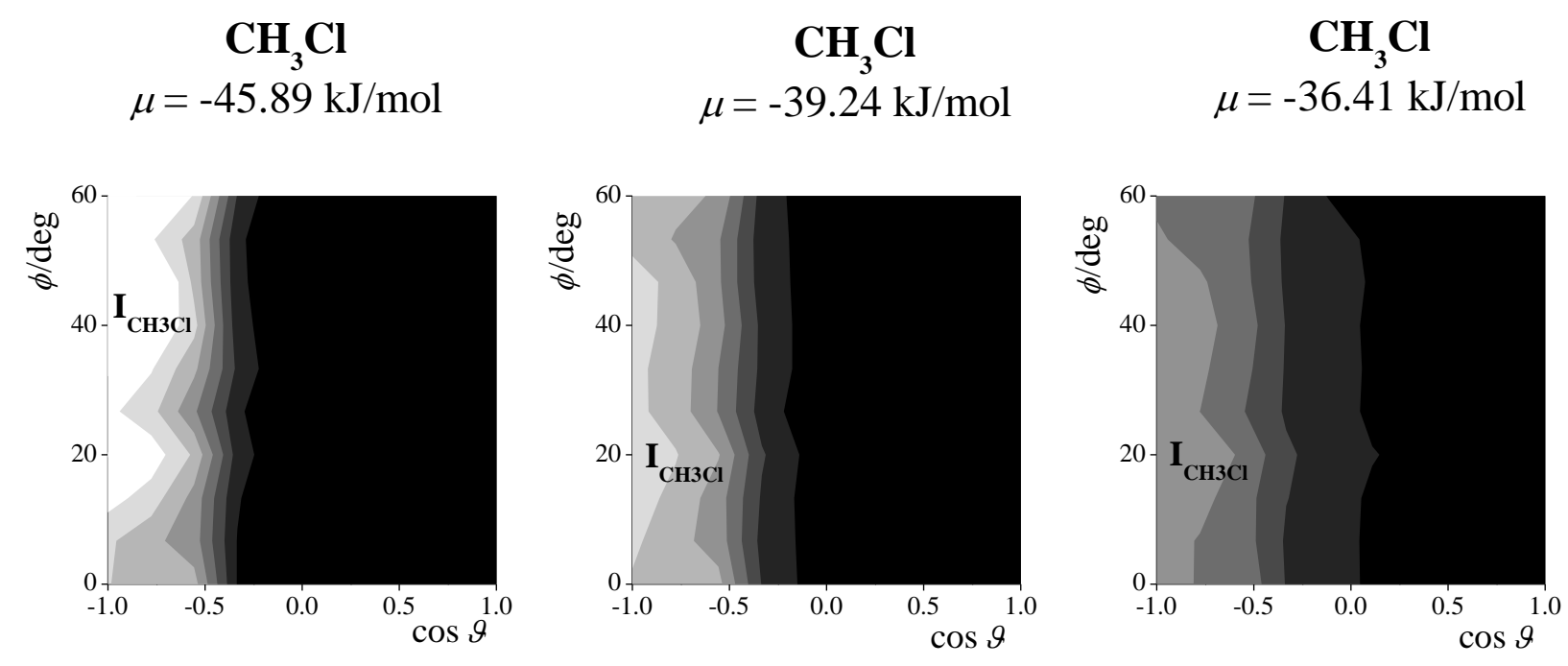

$$
\begin{gathered}
\mathbf{C H}_{\mathbf{3}} \mathbf{C l} \\
\mu=-36.08 \mathrm{~kJ} / \mathrm{mol}
\end{gathered}
$$
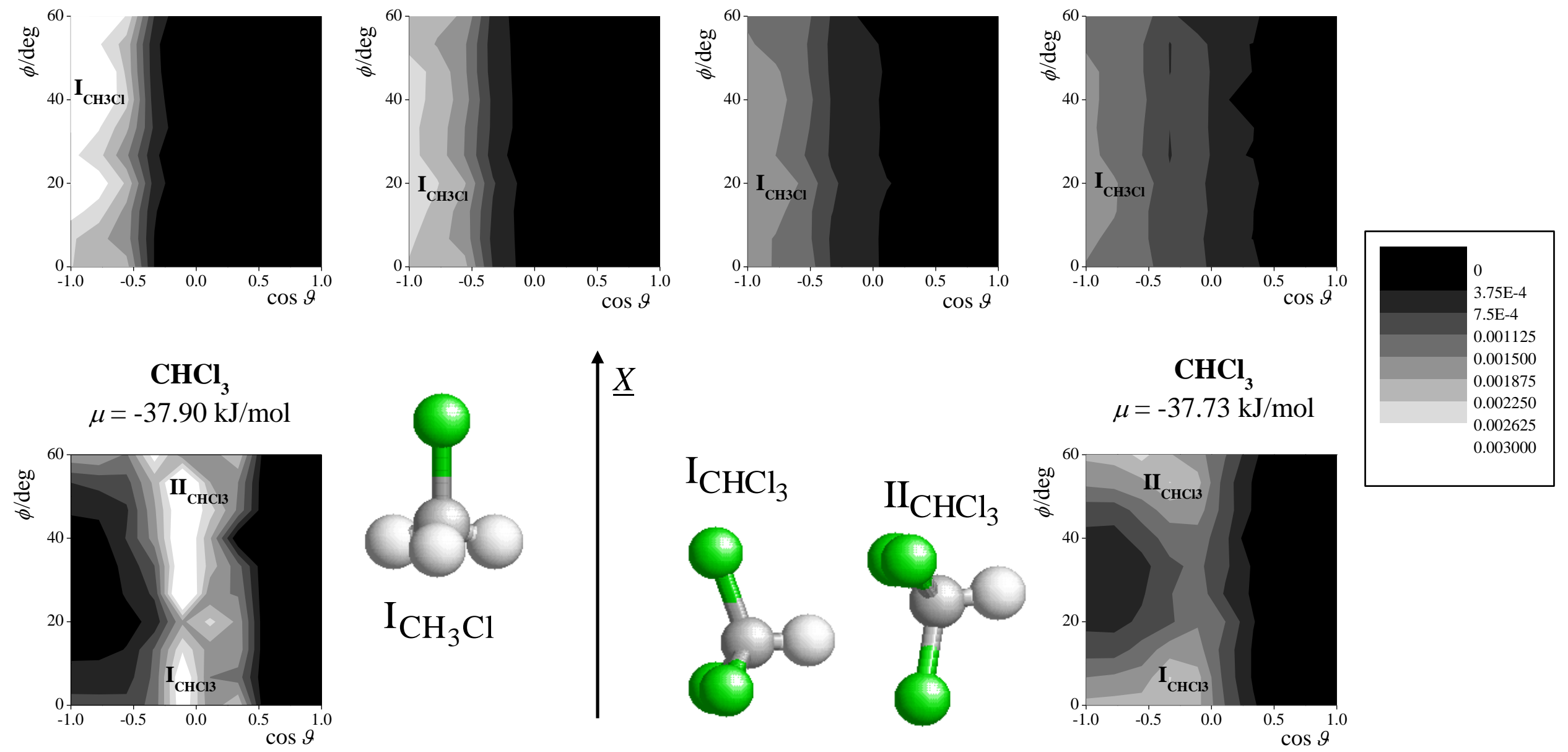
Figure 7.a

Sumi et al.

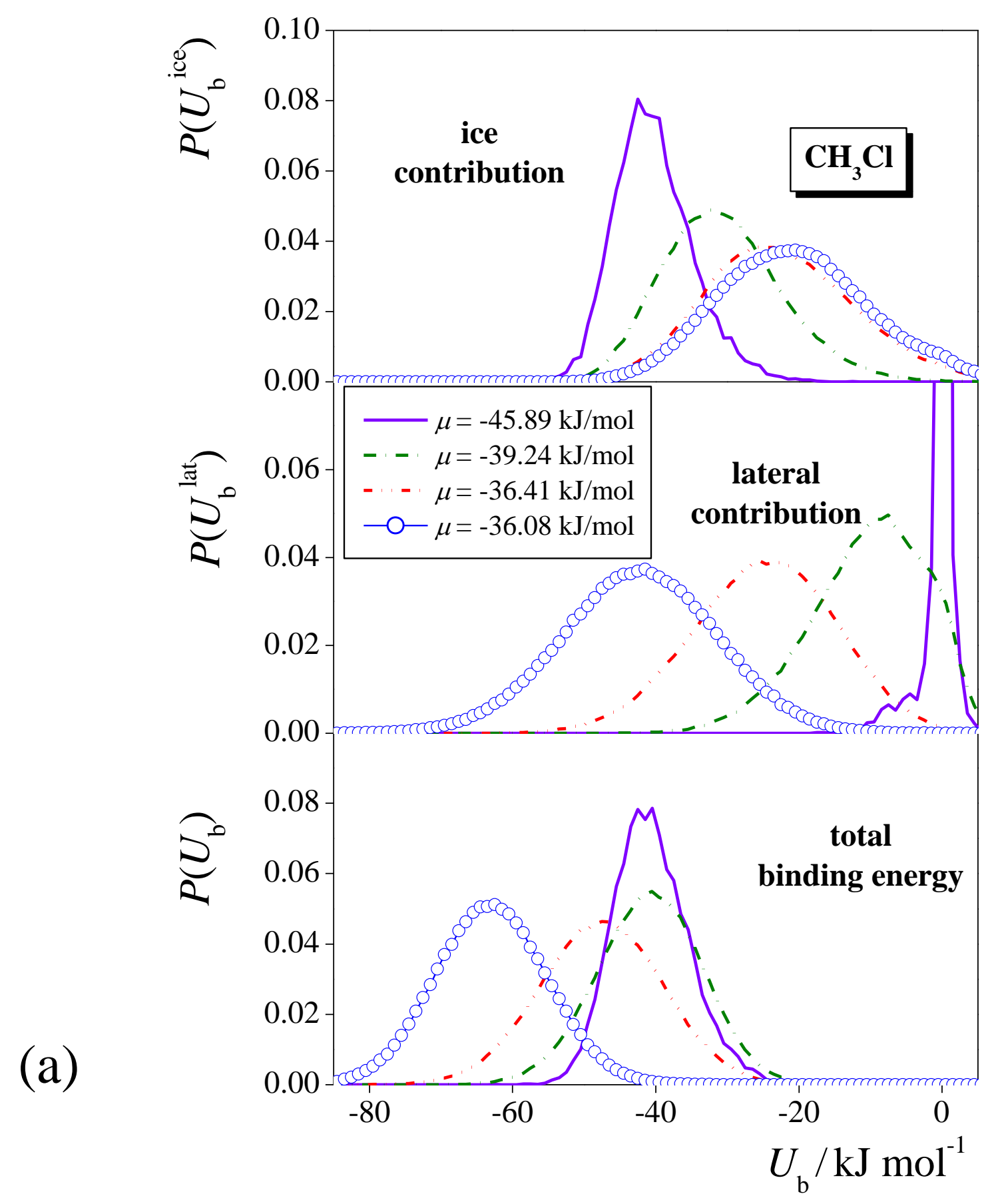


Figure 7.b

Sumi et al.

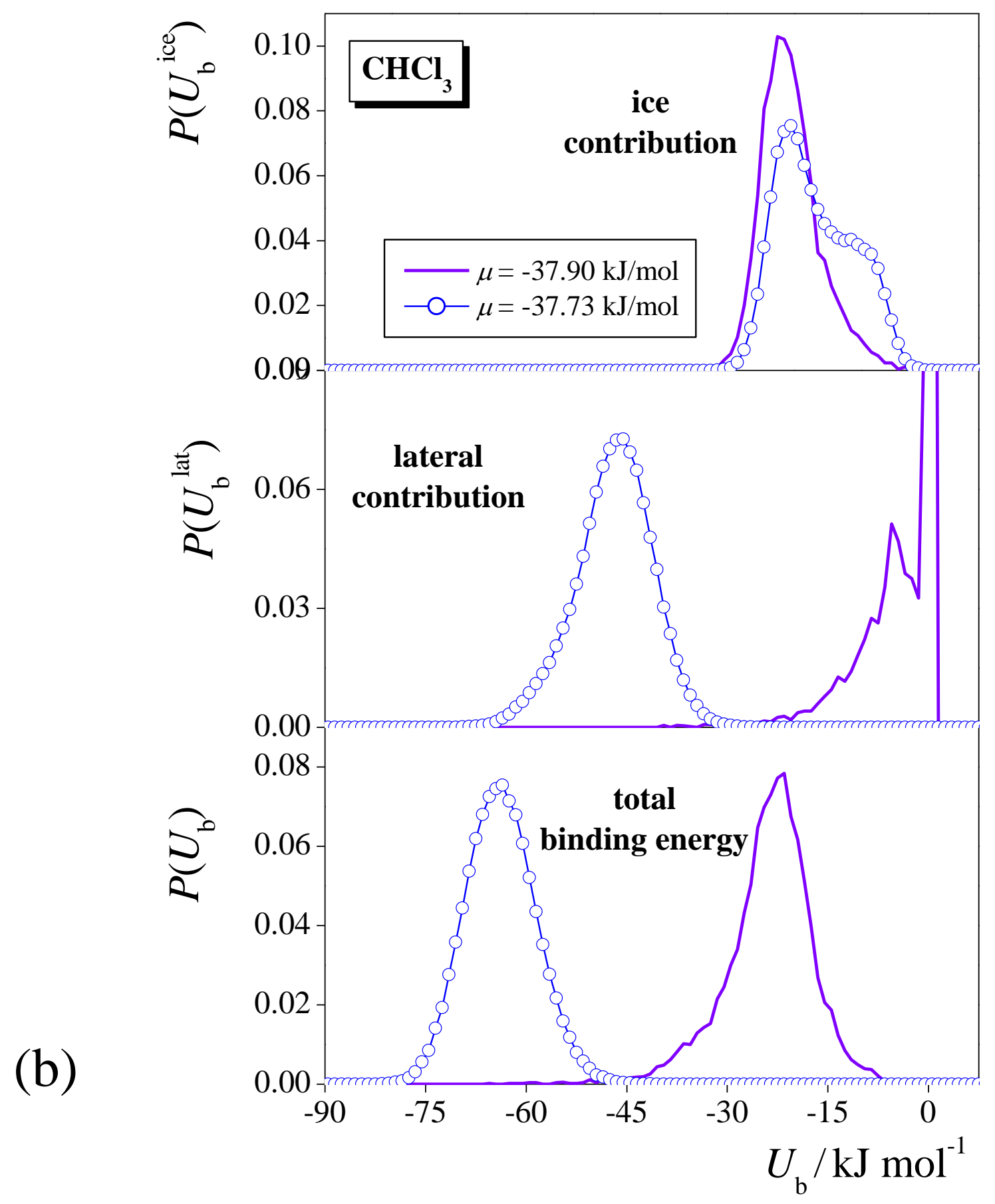


Table of Contents Graphics:

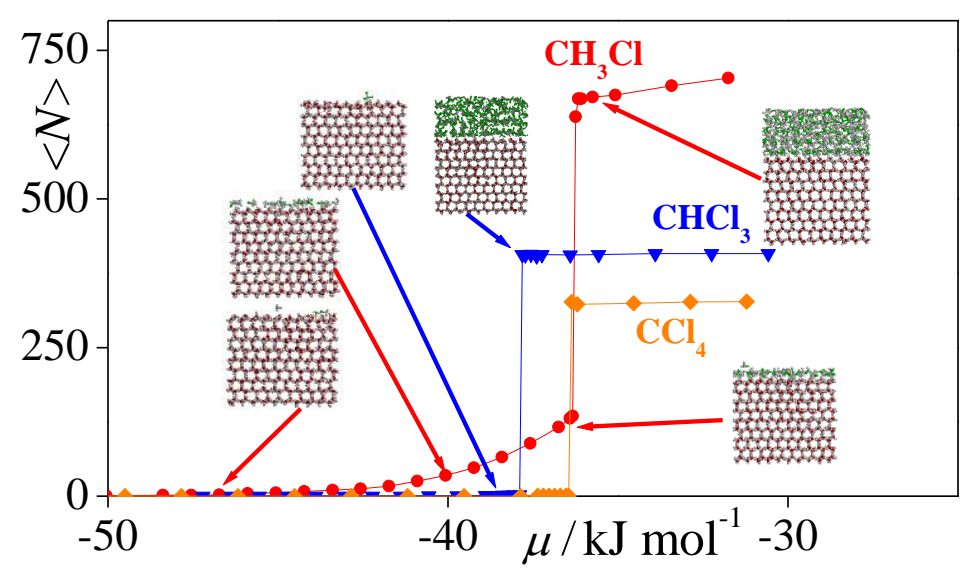

